NBER WORKING PAPER SERIES

\title{
ARE THE GAINS FROM FOREIGN DIVERSIFICATION DIMINISHING? ASSESSING THE IMPACT WITH CROSS-LISTED STOCKS
}

\author{
Karen K. Lewis \\ Sandy Lai \\ Working Paper 18627 \\ http://www.nber.org/papers/w18627 \\ NATIONAL BUREAU OF ECONOMIC RESEARCH \\ 1050 Massachusetts Avenue \\ Cambridge, MA 02138 \\ December 2012
}

We thank Choong Tze Chua, Magnus Dahlquist, Gangadhar Darbha, Bernard Dumas, Vihang Errunza, Bob Hodrick, Andrew Karolyi, Craig MacKinlay, David Ng, Paolo Soderlind, Jessica Wachter, Frank Warnock, Amir Yaron, and participants at the Darden Emerging Markets Conference, Duke University, the International Monetary Fund, the Kansas City Federal Reserve Bank, Singapore Management University, the Society for Financial Econometrics Meetings, the Swedish Institute for Financial Research, and the Wharton Finance and International Finance lunch seminars for useful comments and suggestions. We acknowledge funding from the Wharton-SMU Research Center at Singapore Management University. Of course, any errors are our responsibility. The views expressed herein are those of the authors and do not necessarily reflect the views of the National Bureau of Economic Research.

NBER working papers are circulated for discussion and comment purposes. They have not been peerreviewed or been subject to the review by the NBER Board of Directors that accompanies official NBER publications.

(C) 2012 by Karen K. Lewis and Sandy Lai. All rights reserved. Short sections of text, not to exceed two paragraphs, may be quoted without explicit permission provided that full credit, including $(\subset$ notice, is given to the source. 
Are the Gains from Foreign Diversification Diminishing? Assessing the Impact with Cross-listed Stocks

Karen K. Lewis and Sandy Lai

NBER Working Paper No. 18627

December 2012

JEL No. C32,F36,G15

\begin{abstract}
$\underline{\text { ABSTRACT }}$
How important is foreign diversification? In this paper, we re-examine this question motivated by findings from the literature about foreign companies that are listed on US exchanges. Specifically, domestic portfolios including cross-listed stocks can provide the same diversification as foreign market returns without the need for US investors to go abroad. At the same time, the betas of these foreign stock returns against the US market increase after cross-listing, suggesting diversification worsens over time. In this paper, we assess the impact of these changes on foreign diversification for a US investor. We test for and estimate breaks in the sensitivity of individual foreign stocks listed on US exchanges. We find that roughly half of the changes in betas arise from greater integration between the U.S. and the companies' home markets, not in the companies betas themselves. Moreover, the gains from diversifying into these stocks has declined over time.
\end{abstract}

Karen K. Lewis

Department of Finance, Wharton School

$2300 \mathrm{SHDH}$

University of Pennsylvania

Philadelphia, PA 19104-6367

and NBER

lewisk@wharton.upenn.edu

Sandy Lai

School of Economics and Finance

Hong Kong University

Room 908. 9/F, K.K. Leung Building

Pokfulam Road, Hong Kong

sandy_lai@hku.hk 
Over the past few decades an increasing number of companies have listed their equities across international borders. The availability of these stocks on the exchanges of international markets has put them at the nexus of academic and policy discussions about the degree of integration of financial markets. These discussions have generated sometimes conflicting different themes. On the one hand, the domestic availability of foreign stocks may provide international diversification for domestic investors without these investors having to directly invest abroad. As such, these stocks allow for a relatively low transaction cost way to acquire foreign assets. ${ }^{1}$ On the other hand, the betas of these foreign company stock returns against the domestic market returns tend to increase after cross-listing, mitigating the potential for diversification. ${ }^{2}$ Moreover, the ability to cross-list in another market is often taken as a sign of liberalization for emerging markets. ${ }^{3}$ Therefore, periods when many stocks cross-list from a given country may coincide with changes in the comovement between that country and the rest of the world. As such, higher betas after crosslisting from a foreign stock and the U.S. market may simply reflect a change in betas from the company's home market due to liberalization.

Combining these observations leads to important questions. Since betas against the domestic market increase after cross-listing, how much does this reduce the ability to use these stocks for foreign diversification without the need to invest abroad? And does this change in foreign company betas arise from a greater integration of the home country of that company, consistent with liberalization notion?

To address these questions, we study the diversification potential for foreign stocks before and after they are listed in the US exchanges. We first analyze the local market behavior of foreign

\footnotetext{
${ }^{1}$ See Errunza, Hogan, and Hung (1999) as well as the discussion below.

${ }^{2}$ On the changes in domestic betas, see for example Foerster and Karolyi (1999) and the survey by Karolyi (2006).

${ }^{3}$ Indeed, some papers have used the earliest date when a domestic company could list abroad as a proxy for liberalization while others have used the dates when domestic prices reflect world markets. For example, Bekaert, Harvey, and Lumsdaine (2002) and Henry (2000) use cross-listing dates as one of the liberalization date proxies. Also, Bekaert and Harvey $(1995,1997)$ analyze the time series process when domestic equity prices switch from domestic to international pricing.
} 
stocks listed in the two major stock exchanges in the United States, the New York Stock Exchange and NASDAQ. We then examine whether and how their asset pricing sensitivities to the US market have changed over time. In order to allow for potential shifts in asset pricing characteristics at any point in time, we do not want to impose a change at the cross-listing date unlike the existing literature. Therefore, we require an empirical approach that allows for, but does not require, changes in asset pricing characteristics over time. We also need a framework considers discrete changes in stock price behavior to be consistent with both the emerging market liberalization literature and the event study approach used in the cross-listing literature. We therefore use the break-date estimator of Bai and Perron (1998). For each stock price in local markets, we first test for the number of breaks and estimate the break dates, if any are detected. We then use the parameter estimates before and after these dates to provide a time series of asset pricing characteristics for each stock. From this panel set of estimates we form portfolios of foreign stocks and consider how much risk reduction would be provided to a U.S. investor from these portfolios.

Our analysis delivers three main results that address the questions above. First, a large proportion of foreign cross-listed companies do show evidence of a shift in their betas against the U.S. market, consistent with the literature. Moreover, the evidence suggests that for about $80 \%$ of these companies there is only one break. Second, however, much of the shifts in company betas against the U.S. market appear to be driven by changes at the country level. In particular, roughly half of the foreign company returns do not show any further evidence of shifts in betas once conditioned on the relationship between their home market and the U.S. market. This result suggests that the apparent shifts in the company betas may simply reflect a broader market shift, consistent with the liberalization literature. Third, the foreign betas against the U.S. markekt are generally increasing over time, both for the cross-listed companies and their home markets. ${ }^{4}$ As a result, we find that

\footnotetext{
${ }^{4}$ This tendency may reflect a greater increase in institutional investor ownership. Bartram, Griffin, and Ng (2012) find that cross-listed stocks become more highly correlated with the new owner's other stock holdings after listing.
} 
the potential variance reduction possible through holding these foreign securities is declining over time.

While our results are consistent with finding noted in the literatures above, our approach allows us to investigate new questions. For example, as in the literature on cross-listing events, we find that betas against the U.S. market tend to be higher after this event. But we do not need to condition on this event. Moreover, we can decompose the changes into changing betas at the country versus company level. Also, as in the diversification literature, we find that foreign cross-listed stocks provide hedging opportunities. However, we also can analyze changes in the diversification benefits of these stocks over time.

Finally, as in the liberalization literature, we test for and find breaks in the relationship between foreign country and the U.S. market returns. For example, Bekaert, Harvey, and Lumsdaine (2002) also use the Bai-Perron estimator to test for breaks in asset pricing relationships to date the implicit liberalization events for some emerging market economies. ${ }^{5}$ While we share the use of the BaiPerron methodology, there are important differences in our empirical strategy. Bekaert, Harvey, and Lumsdaine study breaks in emerging market indices using vector-auto-regressions including macro-economic variables that might be correlated with liberalization. By contrast, we test for breaks at the individual firm level and examine the implications for parameters in event time in keeping with the event study-driven cross-listing literature. To our knowledge, this paper represents the first study to analyze the potential for individual breaks for a large number of stocks and then study the resulting portfolio implications. Moreover, while companies from emerging markets are represented in our cross-listed portfolios, we are interested in the full range of foreign companies including those from developed markets as well. ${ }^{6}$ Finally, our analysis allows us to consider whether

\footnotetext{
${ }^{5}$ Another approach used to examine liberalization is to estimate a regime switching model. An early example in the literature is Bekaert and Harvey (1995) while a more recent example that allows for regime-specific spillovers is Baele (2005).

${ }^{6}$ We discuss how our estimates compare the the Bekaert, Harvey and Lumbdaine (2002) results below.
} 
the individual firm returns reflect breaks at the country level, as noted earlier.

The paper is organized as follows. Section 1 gives an overview of the empirical framework including the data and methodology. Section 2 reports the break date and parameter estimates for the foreign companies as well as their home markets. To gain insight into the economic significance of these parameters, Section 3 considers a thought experiment in which a US investor observes these parameters and then attempts to optimally diversify risk. Section 4 evaluates the robustness of our results to various assumptions. Section 5 provides concluding remarks.

\section{The Empirical Framework}

In this section, we first describe the data and the basic asset pricing framework assuming no changes in asset return behavior. In this framework, returns depend upon both local and foreign factors in keeping with the cross-listing and liberalization literatures. We then develop the empirical methodology that allows for potential changes in the sensitivity of foreign returns to the US, but does not impose any changes a priori. Finally, we preview our thought experiment to evaluate the economic impact of the diversification gains.

\section{$1.1 \quad$ Data}

To address the questions posed in the introduction, we require a data set of foreign company returns listed in the United States with sufficient history after cross-listing to analyze potential changes. For this purpose, we choose foreign companies that are listed in the United States in July 2004 since this date implies at least five years of data before the financial crisis in $2009 .{ }^{7}$ Our analysis therefore provides a clear picture of an investor's decision in 2004. However, we are also interested in how the set of stocks may have changed over time, both before 2004 and afterwards. To examine

\footnotetext{
${ }^{7}$ Similarly, Sarkissian and Schill (2009) choose 1999 because they focus upon long run returns after cross-listing of up to ten years.
} 
how the investability of foreign stocks before 2004 would have affected diversification, we consider various assumptions about when these stocks became available to US investors below. The effects of changes after 2004 are more straightforward, however. The set of stocks after 2004 is relatively stable since less than 1\% of our sample was delisted by 2009 .

Foreign stocks trade on a variety of exchanges in the US, including the over-the-counter market (OTC) and institutional investor-only markets (RADR, 144A). In this paper, we restrict the analysis to foreign stocks on the public exchanges for two main reasons. First, our goal in this paper is to consider foreign company diversification from the viewpoint of a representative small US investor, not investments that are only available to large institutional investors. Second, OTC stocks do not require the same level of disclosure requirements as do domestic and foreign stocks on the public exchanges. As such, domestic investors may consider these foreign stocks to have higher information costs. Moreover, the market value of these stocks tend to be quite small.

Exchange-traded foreign companies in the US primarily trade on the NYSE and NASDAQ. ${ }^{8}$ In this study, we use weekly stock returns in foreign markets for parent non-US companies that were traded on the New York Stock Exchange or NASDAQ in 2004. The time period is from January 1970 or the earliest date of availability to October 2009. All return series are measured in US dollars to represent the value from the point of view of a US investor.

For non-Canadian companies, the data were collected in the following steps. ${ }^{9}$ In the first step, a data set of all foreign companies with stocks listed on the New York Stock Exchange were obtained from the Bank of New York, the primary custodian bank for ADRs in this country. This set was cross-checked with listings from the NYSE itself and JP Morgan, another ADR custodian bank. In the second step, the company stock returns in the home market and market values for the full

\footnotetext{
${ }^{8}$ In 2004, the market value of foreign stocks on the NYSE and NASDAQ together comprised $98 \%$ of the total market value across public exchanges. At the 2000 peak of NASDAQ, the foreign companies hit a max of $27 \%$ of this total. Thus, the companies listed on NYSE comprise most of the foreign market cap in the US. In 2004, only 10 foreign companies were traded on the AMEX and we exclude them for simplicity.

${ }^{9}$ More details about the construction of the data are given in Appendix A of the paper.
} 
available history were collected from Datastream.

Canadian companies trade directly on US exchanges without ADR registration. As such, these companies are not listed on custodian bank ADR directories. Instead, we used the Canadian companies on the U.S. exchanges from Doidge, Karolyi, and Stulz $(2004,2005) .{ }^{10}$

To measure the local market index returns, we use the Data Stream Total Market indices for the home market of each foreign company that lists in the US. ${ }^{11}$ Weekly returns are constructed for each of these indices reconverted into US dollars from 1970, or the earliest available, until October 2009. The returns are transformed into excess returns by subtracting the weekly T-bill rate. We do not generally require that US investors can invest in foreign market indices over time. We only assume that these returns mimic the factors that US investors view as important drivers in foreign return behavior.

Table 1 provides summary information about this data set. Panel A reports on the breakdown of firms across exchanges and industries. NYSE has 380 companies coming from 39 foreign countries, while 196 foreign companies domiciled in 28 foreign countries are listed on NASDAQ. There are three foreign countries represented on NASDAQ but not NYSE, Malaysia, Singapore, and Sweden. Thus, the total number of foreign countries represented on the two exchanges is 42 . Panel A also gives the number of different industries represented. ${ }^{12}$ NYSE trades the equity of foreign companies coming from all 47 industries, while NASDAQ foreign companies only produce in 40 industries. Finally, Panel A shows that the foreign companies listed on NYSE are generally older than those on NASDAQ. The average number of observations across firms on the NYSE is 1092, or about 21 years, while that same average across firms on NASDAQ is 862, or about 17 years.

Panel B of Table 1 breaks down the information by the home country of the company. The

\footnotetext{
${ }^{10}$ We thank Andrew Karolyi for providing the names for the Canadian companies used in these papers.

${ }^{11}$ The index includes reinvested dividends converted into US dollars.

${ }^{12}$ This breakdown uses the JP Morgan industry categorization.
} 
first column gives the date at which the market index data begin for each country, ranging from January 5, 1973 for many countries to June 24, 1994 for Portugal. The columns to the right provide more information about the composition of the foreign company presence on each exchange. The home country of the largest number of foreign companies is Canada, followed by the United Kingdom. Emerging markets generally have the lowest number of foreign companies on the exchanges. Moreover, the average number of observations from these foreign companies is generally lower. For example, the Phillipines has only two companies on the NYSE and one company on NASDAQ, and across these three companies the average number of weekly observations is 411 or about 8 years. Below we will discuss the impact of the differing number of observations across countries on the results.

\subsection{Asset Pricing Framework}

Standard factor pricing models used in the literature on international stock returns typically have the form:

$$
r_{t}^{i \ell}=\alpha^{i \ell}+\beta^{i \ell \prime} f_{t}^{\ell}+e_{t}^{i \ell}
$$

Where $r_{t}^{i \ell}$ is the nominal return on the equity of company $i$ that is domiciled in country $\ell$ at date $t$ in excess of the investor's risk free rate, $f_{t}^{\ell}$ is a vector of factors at time t that affect the returns on stocks from the equity market of country $\ell, \beta^{i \ell}$ is a vector of factor intensity parameters for firm $i, \alpha^{i \ell}$ is a constant parameter and $e_{t}^{i \ell}$ is a residual. Since all the analysis below requires excess returns, we will simply call these variables returns throughout the rest of the paper.

The cross-listing literature often uses a one or two factor version of this model as the benchmark for conducting event studies. For example, Sarkissian and Schill (2009) examine the effects of cross- 
listings by firms around the world using market models of the form: ${ }^{13}$

$$
r_{t}^{i \ell}=\alpha^{i \ell}+\beta^{i \ell l} r_{t}^{\ell}+e_{t}^{i \ell}
$$

Where $r_{t}^{\ell}$ is the local market return so that equation (1) is the standard closed economy CAPM, and of the form:

$$
r_{t}^{i \ell}=\alpha^{i \ell}+\beta^{i \ell} r_{t}^{\ell}+\beta^{i u} r_{t}^{u}+e_{t}^{i \ell}
$$

Where equation (2) includes the return of the foreign market in which the stock is cross-listed. Since we only consider companies that are cross-listed in the US, $r_{t}^{u}$ refers to the US market return below. Furthermore, we focus upon the U.S. return in equation (2) because we are interested in examining the sensitivity of the foreign company returns on the US market.

While the cross-listing literature has focused upon the parsimonious two factor model, there may be more factors that are important for explaining international stock returns. For example, Karolyi and $\mathrm{Wu}$ (2012) examine a multi-factor model of international returns but find the importance of a hybrid model that depends upon "global" and "local" factors. Similarly, Bekaert, Hodrick, and Zhang (2009) show that a factor model that includes additional global and local Fama-French factors best explains the returns of companies that comprise the MSCI World Index. If these factors are important for explaining the foreign companies listed in the US, they will appear in the residuals and may affect the variance of residuals. Below we describe analysis to explore the impact of these ommissions.

\footnotetext{
${ }^{13}$ Sarkissian and Schill (2009) also consider a third model that substitutes the world market return for the foreign market. Preliminary estimates based upon the world market instead of the US market obtained similar results to those reported below.
} 


\subsection{Parameter and Break-date Estimation}

While the basic factor model has been used throughout international asset pricing studies, a number of studies have shown that the parameters change over time. In studies of cross-listing events, for example, the parameters are often allowed to shift at the time of cross-listing with significant changes. ${ }^{14}$ Similarly, analyses of market liberalizations such as Henry (2000, 2003) often consider regime changes on the liberalization date that make the local market return depend upon the world return. Furthermore, a large literature has found that the variance and covariances of international stock returns are time-varying. ${ }^{15}$

Given this evidence, therefore, we require an empirical strategy that allows the factor loading parameters to shift on given dates, potentially discretely. But we also need a framework that does not force the shift to occur at a point in time or at all. For this purpose, we use the break date estimator developed by Bai and Perron (BP) (1998). This estimator finds the date or dates in the time series when the factor sensititives are most likely to have changed. ${ }^{16}$ Bekaert, Harvey and Lumsdaine (2002) use this estimator to date liberalizations at the market level. By contrast, we use the estimator to recover a time series of parameters. for each foreign company in our sample. Given this time series for each firm, we build a market-weighted portfolio of these companies.

To understand the estimation procedure, we first describe the basic BP framework in a single equation case before explaining how we extend this analysis to build up a cross-section of these time-series estimates.

\footnotetext{
${ }^{14}$ For example, Foerster and Karolyi (1999) let the alphas and betas on local and foreign markets shift at the event date. Recently, Sarkissian and Shill (2009) assume that only the betas shift at the event date. See the survey in Karolyi (2006) for other examples.

${ }^{15}$ For early works examining the relationship between shifting variances and market liberalizations see Bekaert and Harvey (1995, 1997). Bekaert, Hodrick and Zhang (2009) use time-varying betas to find the best fitting factor model for the set of companies in the MSCI World Index.

${ }^{16}$ The estimator can also be interpreted as a more gradual change in parameters that cumulates into a significant change at a given time. See Bai and Perron (2003a).
} 


\subsubsection{Single-Equation Estimation}

The BP estimator requires specifying a maximum number of breaks in the parameters. Therefore, our analysis begins by estimating this number of breaks. For now, we assume that this number of breaks is simply given as $m$, although we estimate this number below. To economize on notation for developing the estimator to be used below, we subsume the firm superscripts and rewrite the general factor model in (1) as:

$$
r_{t}=\delta^{\prime} f_{t}+e_{t}
$$

where $r_{t}$ is the asset return series, $e_{t}$ is the residual, and $\delta$ is the parameter vector $\delta=\{\alpha, \beta\}^{\prime}$ and where $f_{t}$ is rewritten to include a constant as the first factor. Clearly, the specifications in equations (1) and (2) can be subsumed into this framework.

We then consider $m$ potential shifts in the parameter vector $\delta$, so that the model in equation (3) can be rewritten as:

$$
r_{t}=\delta_{\tau}{ }^{\prime} f_{t}+e_{t}
$$

where $\delta_{\tau}$ is a fixed parameter vector for each period $\tau, \tau=1, \ldots, m+1$ on the intervals implied by:

$$
t=\left\{1, \ldots, T_{1}, T_{1}+1, \ldots, T_{2}, T_{2}+1, \ldots, T_{3}, \ldots, T_{m}, \ldots, T\right\}
$$

for $T_{0}=0$ and $T_{m+1}=T$. For instance, $\tau=1$ corresponds to the subperiod $t=1, \ldots, T_{1}, \tau=2$ corresponds to the subperiod $t=T_{1}+1, . ., T_{2}$, etc. Note that the constant parameter model in equation (3) is a special case of equation (4) where $m=0$ and thereby $\tau=1$ corresponds to the full sample $t=1, \ldots, T .^{17}$

Bai and Perron (1998) show that unknown breakpoints can be estimated consistently by mini-

\footnotetext{
${ }^{17}$ Stock (1994) describes the difficulties between testing for structural breaks versus parametric changes that would suggest non-stationarity. As Bai and Perron (2003a) show, the algorithm for the model to be estimated below can be extended to threshold switching models.
} 
mizing over the sum of squared residuals for all possible partitions of the data into $m+1$ different intervals. In other words, $T_{1}, T_{2}, \ldots, T_{m}$ can be consistently estimated by solving the following minimization:

$$
\left\{\widehat{T}_{1}, \widehat{T}_{2}, \ldots, \widehat{T}_{m}\right\}=\underset{T_{1}, T_{2}, \ldots, T_{m}}{\arg \min }\left[\sum_{\tau=1}^{m+1}\left(\sum_{t \in\left\{T_{(\tau-1)}, \ldots, T_{\tau}\right\}}\left[r_{t}-\delta_{\tau}^{\prime} f_{t}\right]^{2}\right)\right]
$$

Bai and Perron (1998) also derive the limiting distribution of these break point estimates including confidence intervals on the breakpoint estimates.

While the estimation of the break dates requires minimizing the sum of squared residuals for all possible $m$ partitions of the data, Bai and Perron (2003b) show that the estimator can have poor properties when the minimal length of the partition becomes too small. The reason is intuitively clear - finer partitions of the intervals imply fewer observations and, therefore, less precise estimates. Bai and Perron (2003b) propose constraining the minimal length of any partition segment used to calculate the sum of squares in the argmin calculation in equation (5). They define this minimal length as $h \equiv \min \left(\widehat{T}_{(\tau-1)}+1,,, \widehat{T}_{\tau}\right) \forall \tau$ and specify the parameter as proportional to the total sample size. That is, they define a percentage "trimming" constraint $\varepsilon$ to construct the minimal length of a segment: $\varepsilon=h / T$. Bai and Perron (2003b) show that the size of this trimming factor depends upon the number of maximum breaks, $m$, and derive critical values based upon this statistic. Bai and Perron (2003a) report Monte Carlo simulations of the finite sample properties of various tests based upon $\varepsilon$, a point to which we return below.

\subsubsection{Multi-Equation Estimation}

The Bai-Perron estimator described above was developed for an individual time series. Since our goal is to provide a cross-sectional as well as time-series picture of the covariation pattern in foreign relative to domestic returns, we apply this framework to multiple equations. That is, we examine 
each company return separately to build up a set of: (a) the number of breaks; (b) the break date estimates and their associated confidence intervals; and (c) the parameters per sub-period interval.

Specifically, we first test for the number of breaks, $m^{i}$, for each company $i$. We then estimate the set of break dates: $\left\{\widehat{T}_{1}^{i}, \widehat{T}_{2}^{i}, \ldots, \widehat{T}_{m}^{i}\right\}$ and $\delta_{\tau}^{i} \forall \tau=1, \ldots, m^{i}+1$. Defining $L$ as the total number of countries and $N$ as the total number of companies, we can rewrite the two factor model for company $i$ allowing for breaks as in equation (2) over all companies $i$ as:

$$
\begin{gathered}
r_{t}^{i \ell}=\alpha_{\tau}^{i \ell}+\beta_{\tau}^{i \ell} r_{t}^{\ell}+\beta_{\tau}^{i u} r_{t}^{u}+e_{t, \tau}^{i \ell} \\
\forall i=1, \ldots, N ; \ell=1, \ldots, L ; \tau=1, \ldots, m^{i}+1
\end{gathered}
$$

Note that the number of parameter shifts, $m^{i}$, differ by company and include as a possibility that $m^{i}=0$; i.e., no breaks. Moreover, no restrictions are placed on the variance of the residual over subperiods. Indeed, the variance will generally change over subperiods and across countries. In the empirical estimates below, the standard errors are also corrected for general conditional heteroskedasticity as in White (1980) and Andrews (1991).

\subsection{Measuring Diversification Gains}

Given the estimated panel of parameters and variances of cross-listed companies, we will evaluate the impact of these changes on foreign diversification. To assess the impact of these changes, we consider a representative US investor who seeks to reduce the variability in his equity portfolio using foreign equity. To focus upon the relationship between the US and foreign markets, we form a market-weighted portfolio of the foreign companies with returns defined by $r_{t}^{F}$, and as the other portfolio use the US market with return, $r_{t}^{u}$. For comparison with companies not listed in the US, we also consider portfolios of the foreign market indices as well defined as $r_{t}^{L}$. 
To evaluate the benefits of diversification, we focus upon the minimum variance allocation for three main reasons. First, variance reduction has been the focus of much of the international diversification literature since its main motivation arises from the risk-reduction potential. ${ }^{18}$ Second, studies examining optimal portfolio choice based upon mean estimates have found that portfolio allocations respond to the market that has been doing well, but will not necessarily reflect expected future returns. ${ }^{19}$ Third, an extensive literature has found that the excess returns are typically insignificantly different from zero implying imprecisely measured portfolio shares. ${ }^{20}$ Thus, recent studies such as Bekaert, Hodrick, and Zhang (2009) ignore variations in alphas and focus exclusively on the implications of betas on the variability of returns.

When returns are exogenous and i.i.d., minimum variance optimization implies portfolio allocation weights for each asset $k$ given by $\omega_{t}^{k}$ such that: ${ }^{21}$

$$
\boldsymbol{\omega}_{t}=\left(\frac{V^{-1} \iota}{\iota^{\prime} V^{-1} \iota}\right)
$$

where $\boldsymbol{\omega}_{t}$ is the $K \times 1$ vector of optimal portfolio shares $\omega_{t}^{k}, \iota$ is a $K$ dimensional vector of ones, and $V$ is the variance-covariance matrix of returns. We use this framework below to evaluate different sets of portfolio menus available to the US investor. To evaluate the economic significance of our estimates, we then compare this minimum variance using foreign stocks with the variance using the US market only. As we show below, the diversification gains from long foreign investments are particularly large during the early part of the sample in the 1970s, but decline over time.

\footnotetext{
${ }^{18}$ For a survey, see Lewis (1999).

${ }^{19}$ This point is made in Black and Litterman (1992), among others.

${ }^{20}$ See for example Britten-Jones (1999). Using a Bayesian approach, Pastor (2000) evaluates the perceived estimation risk by the investor needed to generate home bias.

${ }^{21}$ For example, Campbell, Lo, and MacKinlay (1997), Chapter 5 gives this solution to the minimum variance portfolio.
} 


\section{Break Date and Parameter Estimation Results}

To examine the potential gains from international diversification using cross-listed companies, we require the parameter and residual variance estimates over time. This section reports the results of testing for potential breaks and then summarizes the distribution of parameter estimates. In Section 3, we will use these results to consider the impact on the minimum variance of the portfolio and evaluate the economic benefits.

Understanding the company level return estimates is complicated by the relationship between returns at the aggregate level between the U.S. and the foreign company stock markets. In particular, the two factor model presumes a stable relationship between the U.S. and foreign markets. Otherwise, we will find instability between foreign company returns and the U.S. market, even if the company returns are stable relative to each market. To see why, recall that the framework for foreign company returns was given by (2), repeated here for convenience:

$$
r_{t}^{i \ell}=\alpha^{i \ell}+\beta^{i \ell} r_{t}^{\ell}+\beta^{i u} r_{t}^{u}+e_{t}^{i \ell}
$$

However, the joint distribution of foreign market returns and the US market returns, $\left\{r_{t}^{\ell}, r_{t}^{u}\right\}$, may itself be changing over time in response to greater liberalization and integration. One approach often used to capture the joint behavior of markets is a standard world CAPM: ${ }^{22}$

$$
r_{t}^{\ell}=\alpha^{\ell}+\beta^{\ell} r_{t}^{u}+u_{t}^{\ell}
$$

Here we have substituted the U.S. market return for the world market return. ${ }^{23}$ Substituting

\footnotetext{
${ }^{22}$ Examples include early papers such as Solnik (1974) and Stehle (1977) and more recently Dumas and Solnik (1995).

${ }^{23}$ This rewriting of the World CAPM requires simply writing each country's return relative to the world market and then substituting out the world return using the US market return.
} 
the country relationship in equation (8) into the company return framework in equation (2) implies:

$$
\begin{aligned}
r_{t}^{i \ell} & =\alpha^{i \ell}+\beta^{i \ell}\left[\alpha^{\ell}+\beta^{\ell} r_{t}^{u}+u_{t}^{\ell}\right]+\beta^{i u} r_{t}^{u}+e_{t}^{i \ell} \\
& =a^{i \ell}+b^{i \ell} r_{t}^{u}+\varepsilon_{t}^{i \ell}
\end{aligned}
$$

Where $b^{i \ell}=\beta^{i \ell} \beta^{\ell}+\beta^{i u}$, and similarly, $a^{i \ell}$ and $\varepsilon_{t}^{i \ell}$ incorporate the combined interactions of the international market returns and the company returns. ${ }^{24}$ Thus, if the relationship between the foreign markets and the US market change over time, $\beta^{\ell}$ will vary so that company returns will appear to be unstable even if $\beta^{i \ell}$ and $\beta^{i u}$ are constant over time. For this reason, we begin this section by estimating the relationship in the market returns given by equation ( 8 ) before returning to the company level relationship in equation (2).

\subsection{Foreign Markets and the US Market Estimation Results}

There are at least three reasons to suspect instability between the US and foreign markets. First, the emerging market literature has demonstrated that liberalizations may induce the market return relationships to endogenously shift. ${ }^{25}$ Second, a number of papers have suggested that the developed markets have become more correlated over time. Third, during crisis times, Longin and Solnik (2001) have argued that markets can become more correlated. As such, higher correlations during crises can undermine the ability to gain from diversification.

We therefore test for stability between the returns in foreign markets and the US allowing for possible parameter shifts in equation (8). This modification gives:

$$
r_{t}^{\ell}=\alpha_{\tau}^{\ell}+\beta_{\tau}^{\ell} r_{t}^{u}+u_{t, \tau}^{\ell}, \text { for } \tau=1, \ldots, m+1
$$

\footnotetext{
${ }^{24}$ In particular, $a^{i \ell} \equiv \alpha^{i \ell}+\beta^{i \ell} \alpha^{\ell}$ and $\varepsilon_{t}^{i \ell} \equiv \beta^{i \ell} u_{t}^{\ell}+e_{t}^{i \ell}$.

${ }^{25}$ On emerging market liberalizations and the effects on stock prices, see for example Bonser-Neal, et al (1990), Bekaert and Harvey (1997,2000), Henry(2000), and Bekaert, Harvey, and Lumsdaine (2002).
} 
where $\tau$ denote subperiods with stable parameters, as before. To avoid confusion, we continue to use $\tau$ as the constant parameter intervals index. However, below we will not require these intervals to be the same for company returns.

Bai and Perron (2003a) describe the properties of various break tests against different alternatives. In particular, the limiting distribution of these tests depends upon the proportion of the minimal subinterval, measured by $\varepsilon$. We conducted the analysis here and throughout the paper assuming $\varepsilon$ is as small as 5\%. However, as the Monte Carlo studies of Bai and Perron (2003a,b) suggest, assuming partitions that are too small can over-estimate the number of breaks. Therefore, to be conservative, we report the estimates based upon assuming $\varepsilon$ is $15 \%$ of the sample but will return to the possibility that breaks occur more often in Section 3 below. ${ }^{26}$

\subsubsection{Country level results: Number of breaks}

Table 2 reports the results of these tests for each of the country regressions in equation (9). The results in Panel A indeed suggest that breaks in the relationship between the US and foreign markets are important. The first three columns report the proportions of the 42 country index returns that reject the hypothesis of no breaks versus the hypothesis of $m$ breaks using the so-called "sup F" test. This test finds the highest $\mathrm{F}$ test for $m$ breaks by considering all the different partitions of subsamples as given in equation (5), subject to the minimum length restriction, $h$. The first column of Table $2 \mathrm{~A}$ shows that the hypothesis of no break against the alternative of at least one break is rejected for $85.7 \%$ of the country indices at a $10 \%$ marginal significance level and even for $81 \%$ of the countries at a $1 \%$ marginal significance level. As the second and third columns show, these proportions become higher when allowing for even more breaks

While Bai and Perron (2003a,b) advocate using the supF test with given numbers of breaks, they

\footnotetext{
${ }^{26}$ In Monte Carlo simulations, Bai and Perron $(2003 \mathrm{a}, \mathrm{b})$ find that the maximal value of $m$ for $\epsilon=0.15$ is 5 . Since $m$ is 4 or less in all the analysis in this paper, our choice of $\varepsilon$ appears relatively conservative.
} 
acknowledge that there are circumstances in which the results might be deceptive. For example, for a regime switching model in which the parameters switch back to an initial regime, the test will underestimate the number of breaks. For this reason, they also suggest testing the hypothesis of no breaks against an unknown number of breaks. The last two columns of Panels A report the proportion of countries that rejected this hypothesis using two versions of the "double maximum" test. The "WD Max" test weights the tests of individual breaks such that the marginal p-values are equal across values of $m$. By contrast, the "UD Max" test weights all values of $m$ equally. Again, the table shows the proportion of countries that reject the hypothesis of no break is significantly higher than the MSL.

Panel B of Table 2 provides summary evidence for the sequential "supF test" given by marginal significance levels (MSL) of $10 \%, 5 \%$, and $1 \%$. In this test, a sequential procedure estimates each break one at a time, and estimation stops when the $\sup F(\tau+1 \mid \tau)$ test is no longer significant at the given marginal significance level. To identify $m^{\ell}$, we conduct sequential SupF tests for each country, allowing up to four subperiods. ${ }^{27}$ The first column of Panel B reports the proportion of the countries that rejected the hypothesis of zero breaks. The last three columns of Panel B report the proportion of countries that show evidence of one break, two breaks and three breaks, respectively. Countries with one break make up the majority of the cases ranging from $61 \%$ at $10 \%$ MSL to $85 \%$ at $1 \%$ MSL. The number of countries with evidence of 3 breaks is smaller at only 3 to $14 \%$.

\subsubsection{Country level results: Break dates}

We next estimate the break date equations for each country return series. Defining $\widehat{m}^{\ell}$ as the estimated number of parameter breaks for country $\ell$, the result of our estimation is a set of break

\footnotetext{
${ }^{27}$ As will be shown below, the country returns show little evidence of more than three breaks anyway, so this assumption for the maximum number of breaks seems fairly conservative.
} 
date estimates for $\ell=1, \ldots, L$ given by:

$$
\left\{\widehat{T}_{1}^{i}, \widehat{T}_{2}^{i}, \ldots, \widehat{T}_{\widehat{m}^{\ell}}^{i}\right\}
$$

and parameter estimates for each interval $\tau=1, \ldots, \widehat{m}^{\ell}+1$ for country $\ell$ given by:

$$
\left\{\widehat{\alpha}_{\tau}^{\ell}, \widehat{\beta}_{\tau}^{\ell}, \widehat{u}_{t, \tau}^{\ell}\right\}
$$

Where the residual is normally distributed with possibly differing variance across intervals,

$$
\widehat{u}_{t, \tau}^{\ell} \sim N\left(0,\left(\sigma_{\tau}^{\ell}\right)^{2}\right)
$$

We thus obtain a set of parameters by subperiod along with break points and confidence intervals around each estimate of the breakpoint and parameters.

Figure 1a plots the break-point estimates for each year by country along with its confidence intervals for the $5 \%$ marginal significance case. The confidence interval for each country excludes the upper and lower $5 \%$ of the estimated break date distribution. The figure shows several relationships. First, except for a few notable exceptions, the confidence intervals around the breaks are contained to within two to three years. Exceptions are the breaks in the late 1970s to early 1980s of Denmark and Ireland and the single break for Taiwan in the 2000s. For countries with additional breaks, subsequent break dates are generally more tightly estimated. Second, most of the breaks occur in the early 2000s. Figure 1b provides another look at this relationship by showing the frequency of breaks over time. Whether looking at only single break countries or over all breaks, the peak of the distribution occurs around 2004. One possibility is that the financial crisis of late 2000s induces a break at the latter part of the sample that is captured around this time. We return to 
this possibility below.

Bekaert, Harvey, and Lumsdaine (2002) use the Bai-Perron estimator in tandem with a vectorautoregression of macroeconomic variables to test for liberalizations. Our focus here is on the risk-sensitivities of cross-listed stocks and as such inclusion dates of our country market indices are driven by the inclusion dates of local-listed companies. Nevertheless, the appendix shows that for countries and data periods in common with Bekaert, Harvey and Lumsdaine (2002), our results are qualitatively similar.

\subsubsection{Country level results: Parameter estimates}

While these figures report the break date estimates in equation (10), Table 3 provides summary statistics about the parameter estimates of equation (11) for the MSL of $5 \% .{ }^{28}$ These statistics are reported for different groupings of portfolios and across pseudo-periods, $\tau$, between breaks. Countries with no breaks have parameters $\delta_{1}^{\ell}$ for the whole period, countries with one break create a new subperiod with estimates $\delta_{2}^{\ell}$ at the same time, etc. ${ }^{29}$ This hypothetical period decomposition allows us to examine the properties of the parameter distribution within subperiods. In our minimum variance portfolio estimates below, we will also report the effects of parameters aligned over calendar year time.

For each portfolio in Table 3, the table reports the cross sectional mean of the beta estimates, their standard errors and their correlations with the US market, labeled $\beta^{\ell}$ Mean, Std Err Mean, and $\operatorname{Corr}\left(r^{\ell}, r^{u}\right)$, respectively. It also gives the cross-sectional standard deviation of the beta estimates given in the row referenced by $\beta^{\ell}$ Std Dev, and the number of countries in the pseudo-sample indicated by "No. of Obs".

\footnotetext{
${ }^{28}$ For the MSLs of $1 \%$ and $10 \%$ the estimates are virtually identical.

${ }^{29}$ More precisely, the pseudo-periods are formed by allocating the estimates for each country into the maximum number of periods. In other words, defining this maximum as $\widehat{m}=\underset{\ell=1, \ldots, L}{\operatorname{Max}}\left\{\widehat{m}^{1}, \ldots, \widehat{m}^{L}\right\}$, the parameter estimates by pseudo-periods are given by: $\delta^{\ell}=\left\{\delta_{1}^{\ell}, \delta_{2}^{\ell}, \ldots, \delta_{m+1}^{\ell}\right\}$ for $\ell=1, \ldots, L$ where $\delta_{\tau}^{\ell}=\delta_{\tau}^{\ell}$ if $\tau \leq \widehat{m}^{\ell}+1$, or $\delta_{\tau}^{\ell}=\delta_{\widehat{m}^{L}}^{\ell}$ if $\tau>$ $\widehat{m}^{\ell}+1$.
} 
Panel A shows the Market Weighted Portfolios and Equally Weighted Portfolios for all countries. Three main features can be seen across these columns. First, the mean betas generally increase over the periods toward one. The market weighted portfolio beta mean is only about 0.35 in Period 1, but is about 0.80 for Period 2. While there are fewer countries with two and three breaks, the means over these later periods increase as well. A similar pattern holds for the Equally Weighted Portfolio. Second, the correlations of these country returns with the US also increase over the periods beginning at about 0.20 for period 1 to 0.36 in period 2 and 0.44 in period 3 . Third, the standard error means have stayed relatively low, generally not exceeding 0.06 so that the hypothesis of beta equal to zero can typically be rejected. Taken together, these parameters are consistent with the general view that markets have become more correlated and integrated over time.

Panel B shows similar results for a market-weighted breakdown of developed countries versus emerging markets. While the mean of the standard errors is higher for emerging markets, the general tendency for mean beta and correlations with the US to rise over time can be seen in both portfolios.

Panel $\mathrm{C}$ details the breakdown of portfolios by regions. In every case, the beta means and correlations increase between periods 1 and 2. In some cases, there is a reversion to a lower beta in the third period but these are based upon sample sizes of two or even one country.

Overall, these results suggest that the relationship between foreign market indices and the US market has shifted over time. The beta of foreign markets on the US has increased towards one and the correlations have also trended upward. We next estimate our relationships between the cross-listed firms and the US markets correcting for the shifts in the home markets over time. 


\subsection{Foreign Companies and the US Market}

As we have noted above, the joint distribution of $\left\{r_{t}^{\ell}, r_{t}^{u}\right\}$ has been unstable over the sample period so that country level breaks will contaminate estimates about the relationship between foreign stocks trading in the US and their relationship with the US market.

This relationship can be seen by substituting the shifting country return process $r_{t}^{\ell}$ from (9) into the company return in (2). This implies:

$$
\begin{aligned}
r_{t}^{i \ell} & =\alpha^{i \ell}+\beta^{i \ell}\left[\alpha_{\tau}^{\ell}+\beta_{\tau}^{\ell} r_{t}^{u}+u_{t, \tau}^{\ell}\right]+\beta^{i u} r_{t}^{u}+e_{t}^{i \ell} \\
& =a_{t}^{i \ell}+b_{t}^{i \ell} r_{t}^{u}+\varepsilon_{t}^{i \ell}
\end{aligned}
$$

Where

$$
\begin{aligned}
& a_{t}^{i \ell}=\alpha^{i \ell}+\beta^{i \ell} \alpha_{\tau}^{\ell} \\
& b_{t}^{i \ell}=\beta^{i \ell} \beta_{\tau}^{\ell}+\beta^{i u} \\
& \varepsilon_{t}^{i \ell} \equiv \beta^{i \ell} u_{t, \tau}^{\ell}+e_{t}^{i \ell}
\end{aligned}
$$

And where, as above, $\tau$ indexes the subinterval in which foreign market indices are stable against the US market return. Thus even if the factor loadings of the foreign stocks on the local and US market, $\beta^{i \ell}$ and $\beta^{i u}$, are not time-varying, an estimate of the parameters in a regression of foreign stocks on the US market, $b^{i \ell}$, would be. This time-variation results from the shifting factor loadings of the local market on the US, $\alpha_{\tau}^{\ell}$ and $\beta_{\tau}^{\ell}$.

At the same time, the relationship between returns on foreign stocks cross-listed in the US and the US market return itself may change for different reasons. Using event studies, a vast literature on international cross-listings has found that a company's cost of capital tends to fall after cross- 
listing. Moreover, the betas of the foreign stock often change against the US. Others such as Baruch and Saar (2009) have argued that the decision to list on an exchange arises from the perception that the company is more similar to other stocks on a given exchange. If there are shifts in individual foreign stock returns as a result of listing in the US market, it is unclear whether these changes would occur before or after the cross-listing. Moreover, these changes in individual stock behavior need not correspond to general features about the relationship between the US market and the company's home market.

\subsubsection{Company level results: Explained by market-level changes?}

We begin our company return analysis by asking whether there are shifts in the relationship between cross-listed stocks and the US market beyond those induced by market level changes. To test this hypothesis, we use the estimates for the parameters of the home country in equation (11) and then test whether there are any additional breaks in equation (12) using the sequential $\sup (\mathrm{F})$ tests. $^{30}$ If rejected, we consider whether the rejection arises from instability in local betas or US betas.

Table 4 reports summary statistics of these tests. Panel A gives a summary of the number and proportion of firms that are domiciled in countries with One Break $(m=1)$, Two Breaks $(m=2)$, and Three Breaks $(m=3)$. The final column labeled "All" shows the proportion of firms with home markets that reject stable parameters for $m \geq 1$. Since this proportion is about $95 \%$, only about $5 \%$ of the firms come from countries with no evidence of structual instability against the US. Another $62 \%$ come from countries with one break, while only $9 \%$ of the firms come from countries that show evidence of two breaks. On the other hand, $24 \%$ of the firms come from countries with three breaks. This latter result is largely due to Canada which has the largest number of

\footnotetext{
${ }^{30} \mathrm{By}$ conditioning the estimation on the first stage country regression parameter estimates, this second stage may suffer from a generated regressions problem that will understate the true standard errors thereby potentially biasing the Wald tests toward rejection. To try to mitigate this possibility, we allow for general conditional heteroskedasticity in the Wald tests.
} 
foreign companies in the US, but also has three breaks potentially arising from its longer history of integration with the US.

Panel B shows the results of the sequential $\sup (\mathrm{F})$ test for the firm returns conditioning on the stock index parameters. The column labeled "No Breaks" indicates that 277 firms or about $49 \%$ of the firms did not show evidence of breaks beyond the country level. The remaining three columns show that the returns from those firms that did reject the hypothesis of no additional breaks appeared to have only one break. In particular, data from 231 firms could not reject the hypothesis of more than one break while 55 firms appeared to have two breaks. The returns from only 6 or about $1 \%$ of the firms indicated three breaks beyond the country level.

For the firms rejecting no parameter instability beyond the country level, Panel $\mathrm{C}$ examines the source of instability. Using the definition for the estimated parameters in equation (12), we identify the firm level parameters over the country subintervals as: $\left\{\beta_{\tau}^{i \ell}, \beta_{\tau}^{i u}\right\}, \tau=1, \ldots, m^{\ell}+1$ and then test a series of Wald tests for each firm. The first two columns report the number of rejections of the hypotheses that each of the two betas are zero for each stock. If the beta on the local market is zero, i.e., $\beta_{\tau}^{i \ell}=0$, then there is no local effect on the stock return during the period as can be seen by substituting into equation (12) which gives:

$$
r_{t}^{i \ell}=\alpha^{i \ell}+\beta^{i u} r_{t}^{u}+e_{t}^{i \ell}
$$

In this case, the stock return depends only on the world CAPM. Alternatively, when the beta on the US market is zero, $\beta_{\tau}^{i u}=0$, the stock depends only on the local effects. Substituting this restriction into equation (12) implies:

$$
r_{t}^{i \ell}=\alpha^{i \ell}+\beta^{i \ell} \alpha_{\tau}^{\ell}+\beta^{i \ell} \beta_{\tau}^{\ell} r_{t}^{u}+\beta^{i \ell} u_{t, \tau}^{\ell}+e_{t}^{i \ell}
$$


Thus, the return from company $i$ depends upon the US market return only indirectly through its beta with the home market, $\beta^{i \ell} \beta_{\tau}^{\ell}$, since its home stock market in turn depends upon the US stock market.

As the first two columns of Panel $\mathrm{C}$ show, the zero beta restriction is rejected for both the local and US betas for most of the firms. However, the proportion of those rejections differ markedly. About $85 \%$ of the firms reject the zero local beta effect while only $58 \%$ of the firms reject the zero US beta effect. The same pattern carries over to the next two columns that report tests for the hypothesis that local and US effects are constant over the sub-periods. Sixty-three percent of the firms reject the hypothesis that the local effects are constant over time while $44 \%$ of the firms reject the test that US effects are stable.

\subsubsection{Company level results: Break dates}

Given the evidence for additional parameter instability for about half of the foreign stocks, we next examine the behavior of returns for these individual stocks more closely. For each of the foreign companies, we estimate the following model:

$$
r_{t}^{i \ell}=\alpha_{\varsigma}^{i \ell}+\beta_{\varsigma}^{i \ell} r_{t}^{\ell}+\beta_{\varsigma}^{i u} r_{t}^{u}+e_{\varsigma, t}^{i \ell}, \quad \text { for } i=1, \ldots, N ; \varsigma=1, \ldots, n^{i}+1
$$

where $r_{t}^{i \ell}$ is as given by equation (9), repeated here:

$$
r_{t}^{\ell}=\alpha_{\tau}^{\ell}+\beta_{\tau}^{\ell} r_{t}^{u}+u_{t, \tau}^{\ell}, \text { for } \ell=1, \ldots, L ; \tau=1, \ldots, m+1
$$

Equation (15) now allows explicitly for the possibility of shifts in the company level returns. Note that the number of breaks and their implied sub-periods may differ for the country and firm returns. In other words, for the returns of firm $i$ in country $\ell$, the estimates allow for $\tau \neq \varsigma, n^{i} \neq m^{\ell}$. As a 
result, the break-dates of the firm may differ from the country returns.

The time interval mapping analogous to equation (4) is then:

$$
t \in\left\{\kappa_{(\varsigma-1)}+1, \ldots, \kappa_{\varsigma}\right\} \text { for } \kappa_{\varsigma} \in\left\{\kappa_{1}, \kappa_{2}, \ldots, \kappa_{n}\right\}
$$

where the estimates of $\kappa_{\varsigma}$ are:

$$
\left\{\widehat{\kappa}_{1}, \widehat{\kappa}_{2}, \ldots, \widehat{\kappa}_{n^{\ell}}\right\}=\underset{\kappa_{1}, \kappa_{2}, \ldots, \kappa_{n} \ell}{\arg \min }\left[\sum_{\varsigma=1}^{n^{\ell}+1}\left(\sum_{t \in\left\{\kappa_{(\varsigma-1)}, \ldots, \kappa_{\varsigma}\right\}}\left[r_{t}^{i \ell}-\delta_{\varsigma}^{i,} f_{t}^{\ell}\right]^{2}\right)\right]
$$

And $\kappa_{0}=0, \kappa_{n^{\ell}+1}=T{ }^{31}$ While the regressions in equation (16) contain both local home country returns and US market returns, these variables are jointly unstable as documented above. Therefore, we condition the firm level estimation on these aggregate market breaks.

As for the country-level estimation, we first estimate the break dates for the roughly $50 \%$ of firms that show evidence of parameter instability. These break dates estimates and their confidence intervals are plotted in Figure 2, where the firms are arrayed according to the firm with the earliest first break through the firm with the latest first break date. Generally, the dates are tightly estimated within one to three years as with the country estimates. However, there are some outliers when these intervals exceed eight years.

\subsubsection{Company level results: Parameters}

Tables 5 and 6 provide summary statistics on the firm return local market beta and US market beta, respectively. These statistics are based upon the same portfolio breakdowns as reported for the country regressions, but with company market capitalization weights.

The local market betas in Table 5 show little change over time. In particular, Panel A shows

\footnotetext{
${ }^{31}$ While the time intervals $\kappa$ depend upon each firm $i$, we subsume the firm superscripts for ease of exposition.
} 
that the market weighted betas increase from subperiod one to two from 0.66 to 0.75 while the equally weighted portfolio betas are essentially flat at around 0.7. Panel B demonstrates that this pattern is robust across companies coming from emerging and developed markets. Moreover, the correlation between the returns and the home market appears to be relatively stable over the subperiods. Panel $\mathrm{C}$ further breaks the information down into geographic regions, conveying some interesting distinctions across these areas. Generally, the companies from Asia and the Middle East \& Africa tend to have lower betas with their home markets at around 0.3 , while the companies from other areas have betas on their home markets closer to one.

Table 6 reports the same summary statistics for the company US market betas. For these portfolio parameters, the means increase more sharply. For the market-weighted portfolio, the US market betas in Period 1 are only 0.455 but increases to 0.792 in Period 2. These mean betas increase even more over the following two periods, peaking at 0.995 by Period 4 , though the means for these latter periods are based upon a much smaller number of observations. A similar but more attenuated pattern hold for the Equally Weighted portfolio. This pattern is also robust to decomposition between the developed and emerging market companies as reported in Panel B.

Interestingly, the correlation between cross-listed company returns and the US market increases over sub-periods. Across all countries, the mean correlation increases from 0.16 in period 1 to 0.32 in period 4. Moreover this pattern holds for the breakdown between developed and emerging market companies as well.

Panel C of Table 6 reports the US market beta statistics for portfolios decomposed into geographic area. For all of the geographic areas, the market-weighted betas of company returns against the US increase between the first and last period. Furthermore, the mean correlation of these stock returns with the US market increases as well, even for companies from developed countries. For example, the correlation between European cross-listed stocks and the US is on-average just 0.16 
in period 1 , but increases to 0.24 in period $2,0.27$ in period 3 and finally 0.34 in period 4 .

Taken together, the parameter results in Tables 5 and 6 suggest that even after controlling for the apparent shift toward integration of market indices, the set of cross-listed companies have become more correlated with the US. First, the indirect relationship with the US market has increased. That is, Table 5 shows that local market betas have increased toward one and since the local market indices against the US has also increased, the product of these betas $\beta^{i \ell} \beta_{\tau}^{\ell}$ has increased. Second, the direct relationship with the US market has increased as well. Table 6 demonstrates that US market betas have increased toward one and the mean correlations with the US have also increased.

\subsection{Cross-Listing Dates and Betas against the US Market}

So far, we have shows that both the foreign cross-listed companies and their home markets tend to co-move more closely with the US market over time. However, the summary statistics do not necessarily say anything about how these relationships have changed before or after cross-listing. A number of papers have conducted event study analysis at the time of cross-listing to examine the impact on returns. For this purpose, the beta coefficients are typically allowed to break at the time of cross-listing. While the usual event study analysis treats the beta coefficients as common across all firms, our estimation is conducted at the firm level and as such our results are not directly comparable with that literature. Nevertheless, we can use our estimates over time to ask whether the parameters we observe before and after cross-listing show a similar pattern.

The emerging market liberalization literature has also used cross-listing events. For example, Henry (2000) uses the earliest date at which a company cross-lists in the economy as a measure of openness. Our country-level estimates also include developed market stock returns so that the earliest cross-listing date may not be relevant for understanding liberalization. However, in our minimum variance portfolio analysis below, the relationship between cross-listed firms and their 
home markets dictate the investor's measures of risk. Therefore, it is also useful to consider how the betas of these foreign markets change when companies from their countries are listed on the US exchanges.

Table 7 reports summary statistics before, after, and during cross-listing for all three betas estimates. Panel A gives the statistics for the country regressions in Table 3. To calculate these statistics, we first array the beta coefficients by year. Then, we sort the betas of the home market on the US, $\beta^{\ell}$, according to their estimates "Before Listing" in the first column, or "After Listing" in the second column if the process shifts after listing. Since the intervals after listing can be somewhat later than the listing date itself, we also report the averages including the listing period under the column labeled "After and During Listing."

A basic pattern is clear from these estimates. For both the Market-Weighted and EquallyWeighted portfolios, the average betas increase significantly after listing. When the "during listing" period is included in the last column, this increase is attenuated, but is still significantly higher than the "before listing" period. Moreover, the pattern in the betas is mirrored in the correlations. The mean correlations increase from around 0.2 before listing to almost 0.4 in the later period excluding listing and is about 0.3 if the listing period is included.

Panel B of Table 7 shows the corresponding breakdown by company betas for the local market, $\beta^{i \ell}$, and the US market, $\beta^{i u}$. While the local market betas show some slight tendency to increase, the difference is not pronounced and is in fact rather flat at around 0.7 for the Equally Weighted portfolio. Furthermore, the correlation of the cross-listed companies with their home markets does not show any real trend, hovering at around 0.2

By contrast, the statistics for company returns relative to the US market show a more pronounced relationship. The mean of company betas against the US increases from about 0.49 before cross-listing to 0.97 for firms that show evidence of parameter breaks after cross-listing. Although 
this mean drops to 0.74 when the listing period is included, it remains considerably higher than the mean before cross-listing. The correlation of these companies with the US follows this pattern as well. Taken together, these parameter estimates suggest that cross-listed company betas and correlations with the US market increase after cross-listing.

\subsection{Summary of Parameter Distribution Results}

So far, we have answered the first three questions posed in the introduction. First, we indeed found evidence of changes in the relationship between the US market and foreign companies that become available on US stock exchanges by 2004. Second, the betas of these companies on the US market appear to have increased over time both directly and indirectly through the effects of greater correlation of the US with the companies' home markets. Third, the timing of these changes suggest that foreign company returns become more correlated with the US after cross-listing.

Taken together, these changes would generally suggest that the gains from diversification should decline over time. However, the potential effects of these changes also depend upon other timevarying relationships such as the residual variance-covariance of the portfolios and the market-

weights Therefore, in the next section, we combine our parameter estimates with these other features to address the economic impact of these changes on a US investor.

\section{The Impact of Integration on Diversification Gains}

Given the panel of parameter estimates above, we are now in a position to address the remaining set of questions described in the introduction. In particular, what are the implications of the shifts in parameters for international diversification by a typical US investor? Specifically, does the increased correlation of these foreign stocks in the US significantly reduce international diversification gains, particularly if investors do not invest in foreign markets directly? And do the more recently listed 
foreign stocks provide greater diversification opportunities to the US investor because they are less correlated with the US market or do these foreign stocks merely mimic the behavior of other foreign stocks that have been previously listed?

\subsection{US Investor Framework}

To address these questions, we require a framework that focuses on minimizing risk. As described in Section I, we construct a simple minimum-variance portfolio of a small US investor's benchmark asset of the US market and a set of foreign equity investments. ${ }^{32}$ We consider different versions of portfolio menus that range from the least restrictive to the most restrictive assumptions about foreign stock availability.

In the less restrictive set of menus, we assume that the investor has access to three different portfolios: (a) the US market portfolio, (b) a market-weighted portfolio of foreign companies listed on the US exchanges, and (c) a market-weighted portfolio of foreign market indices that have companies listed on the US exchanges. Thus, the investor portfolio is comprised of holding the three asset return process: $r_{t}^{p}=\left\{r_{t}^{F}, r_{t}^{L}, r_{t}^{u}\right\}$. This menu set may be unrealistic because the investor is unlikely to have easy access to all the companies in the foreign market indices. Nevertheless, we analyze this portfolio set because it allows us to compare the desirability of holding foreign stocks listed in the US even if the investor were to have direct access to the foreign market index.

In the second set of portfolio menus, we assume that the US investor has access to foreign markets only through foreign stocks listed in the US so he has access only to (a) the US market portfolio and (b) the market-weighted portfolio of foreign companies in the US. Thus, the portfolio returns are given by the process: $r_{t}^{p}=\left\{r_{t}^{F}, r_{t}^{u}\right\}$. This portfolio set may be too restrictive because investors are likely to have access to other forms of international investment. Studying this menu set

\footnotetext{
${ }^{32}$ We assume that the US investor's benchmark portfolio is the US market since this is the most common benchmark used in the international diversification literature. However, other benchmarks could be incorporated. For example, Liu (2012) uses a benchmark of the Fama-French 5 Factor Model for a representative US investor.
} 
allows us to focus upon the diversification potential of cross-listed companies alone if the investor did not have access to any other foreign investments.

Given these sets of portfolio menus, we consider how the US investor would optimally reduce the volatility of his overall portfolio by his allocation among these returns. In general, the minimum variance optimization gives a portfolio allocation based upon the distribution of returns from the portfolio $r_{t}^{p} \equiv \sum_{k=1}^{K} \omega_{t}^{k} r_{t}^{k}$. When the variance is constant over time, the minimum variance portfolio weights are given by equation (7) above. However, our analysis has shown that the variances are time-varying. If the investor believes the variances will not change in the future, the minimum variance portfolio weights are:

$$
\boldsymbol{\omega}_{t}=\left(\frac{V_{t}^{-1} \iota}{\iota^{\prime} V_{t}^{-1} \iota}\right)
$$

where $\omega_{t}$ is the $K \times 1$ vector of optimal portfolio shares $\omega_{t}^{k}, \iota$ is a $K$ dimensional vector of ones, and $V_{t}$ is the variance-covariance matrix of returns at time $t$.

The minimum variance portfolio depends solely upon the variance-covariance matrix. The minimum variance portfolio behavior therefore derives exclusively from the variation in components of $V_{t}$. Recalling the definition of the portfolio of the two market-weighted portfolios above, the market-weighted portfolio of the foreign companies is given by $r_{t}^{F} \equiv \sum_{i=1}^{N} z_{t}^{i} r_{t}^{i \ell}$ where $z_{t}^{i}$ is the market weight of foreign company $i$ at time $t$, while the portfolios of the foreign market indices with companies listed in the US is given by $r_{t}^{L} \equiv \sum_{\ell=1}^{L} x_{t}^{\ell} r_{t}^{\ell}$ where $x_{t}^{\ell}$ is the market weight of market index $\ell$ at time $t$. For our analysis, we consider below alternatively the more restricted portfolio menu, $r_{t}^{P}=\left\{r_{t}^{U}, r_{t}^{F}\right\}$ and the less restricted portfolio menu, $r_{t}^{P}=\left\{r_{t}^{U}, r_{t}^{F}, r_{t}^{L}\right\}$.

\subsubsection{More restrictive asset menu}

We start with the variance-covariance of the more restrictive menu. In this case, the investor considers adding a market-weighted portfolio of foreign stocks traded in the US to his benchmark 
portfolio. In this case, $V_{t}$ is simply a $2 \times 2$ matrix that can be written as:

$$
V_{t}=\left[\begin{array}{cc}
V_{u u, t} & V_{u f, t} \\
V_{f u, t} & V_{f f, t}
\end{array}\right]
$$

where $u$ and $f$ refer to the second moments of the US return, $r^{u}$, and the returns of foreign companies listed in the US, $r^{F}$. Using the foreign returns equations in (15), each component of the variance-covariance matrix can be written in terms of the parameters of the model. First, the US return is the benchmark for the US investor so that its variance is simply: $V_{u u, t}=\sigma_{U}^{2}$. By contrast, the variance components of the foreign companies listed in the US depend upon their factor loadings. The appendix shows that the variance of the portfolio of foreign companies in the US is given by:

$$
V_{f f, t} \equiv \operatorname{Var}_{t}\left(r_{t}^{F}\right)=\sigma_{U}^{2}\left(\widetilde{\mathbf{b}}_{t}^{u}\right)^{2}+\widetilde{\boldsymbol{\beta}}_{t}^{L \prime} \Gamma_{t} \widetilde{\boldsymbol{\beta}}_{t}^{L}+Z_{t}^{\prime} \Omega_{t} Z_{t}
$$

Where $\widetilde{\mathbf{b}}_{t}^{u}$ is the vector of US market sensitivities with typical element, $b_{t}^{i \ell}=\beta_{\varsigma}^{i \ell} \beta_{\tau}^{\ell}+\beta_{\varsigma}^{i u}$ for all time intervals $\tau$ and $\varsigma$, with each element multiplied by company market weights. Similarly, $\widetilde{\boldsymbol{\beta}}_{t}^{L}$ is the vector of local market sensitivities with typical element, $\beta_{\tau}^{\ell}$, weighted by company market capitalizations. $Z_{t}$ is the vector of these market weights. Finally, $\Gamma_{t}$ and $\Omega_{t}$ are the conditional variance-covariance matrices of the innovations to country returns, $u_{\tau, t}^{\ell}$ and company returns, $e_{\kappa, t}^{i \ell}$, respectively.

Thus, there are three components in the variance of foreign companies in the US. First, $\sigma_{U}^{2}\left(\widetilde{\mathbf{b}}_{t}^{u}\right)^{2}$ captures the extent to which foreign returns move with the US market. The lower are the sensitivities to the US, the lower is $b^{u}$ and hence the variance. Second, $\widetilde{\boldsymbol{\beta}}_{t}^{L \prime} \Gamma_{t} \widetilde{\boldsymbol{\beta}}_{t}^{L}$ measures the effect of lower residual variance of foreign markets on the variance of the foreign companies. Once again, this variance will rise and fall with the magnitude of the foreign market sensitivities to the US. 
Third, the variance depends upon $Z_{t}^{\prime} \Omega_{t} Z_{t}$ or the variance of residuals to the market-weighted portfolio of foreign returns.

In light of this description, the covariance between the US and this portfolio of foreign companies is transparent.

$$
V_{u f, t}=V_{f u, t} \equiv \operatorname{Cov}\left(r_{t}^{U}, r_{t}^{F}\right)=\sigma_{U}^{2} \widetilde{\mathbf{b}}_{t}^{u}
$$

The covariance depends only upon the foreign company sensitivities to the US market. As can be seen in equation (15), the factor sensitivities are orthogonalized to the residuals in the country returns and the US return by construction.

\subsubsection{Less restrictive asset menu}

For the less restrictive menu of foreign assets, we augment the set to include the returns from foreign market indices with companies listed in the US, $r^{L}$. In this case, the covariance matrix $V$ becomes a $3 \times 3$ matrix given by:

$$
V_{t}=\left[\begin{array}{ccc}
V_{u u, t} & V_{u f, t} & V_{u \ell, t} \\
V_{f u, t} & V_{f f, t} & V_{f \ell, t} \\
V_{\ell u, t} & V_{\ell f, t} & V_{\ell \ell, t}
\end{array}\right]
$$

Although, the top left hand quadrant of the matrix remains the same, the covariance matrix now has three additional terms. First, the variance of the foreign market index is:

$$
V_{\ell \ell, t} \equiv \operatorname{Var}_{t}\left(r_{t}^{L}\right)=\sigma_{U}^{2}\left(\widehat{\boldsymbol{\beta}}_{t}^{L}\right)^{2}+X_{t}^{\prime} \Gamma_{t} X_{t}
$$

Where $\widehat{\boldsymbol{\beta}}_{t}^{L}$ is the vector of local market betas now weighted by the country market capitalizations. $X_{t}$ is the vector of country index weights. Similar to the variance of the portfolio of foreign 
companies, the variance increases with the betas $\boldsymbol{\beta}^{L}$ and residual variances, $U$.

The covariances of this foreign market return with the US and the foreign companies are:

$$
\begin{gathered}
V_{u \ell, t}=V_{\ell u, t} \equiv \operatorname{Cov}\left(r_{t}^{U}, r_{t}^{L}\right)=\sigma_{U}^{2} \widehat{\boldsymbol{\beta}}_{t}^{L} \\
V_{f \ell, t}=V_{\ell f, t} \equiv \operatorname{Cov}\left(r_{t}^{F}, r_{t}^{L}\right)=\sigma_{U}^{2} \widetilde{\mathbf{b}}_{t}^{u} \widehat{\boldsymbol{\beta}}_{t}^{L}+\widehat{\boldsymbol{\beta}}_{t}^{L \prime} \Gamma_{t} \mathbf{X}_{t}
\end{gathered}
$$

Analogous to the covariance with the foreign company returns, the covariance of the US market with the foreign market indices are given by the product of the market-weighted betas and the US variance. The covariance of the foreign companies and the foreign market indices is comprised of two components. The first component is the US variance weighted by the product of betas for

the foreign companies, $\widetilde{\mathbf{b}}_{t}^{u}$, and betas for the foreign market indices, $\widehat{\boldsymbol{\beta}}_{t}^{L}$. The second component is the country residual matrix weighted by the country betas for the companies, $\widehat{\boldsymbol{\beta}}_{t}^{L}$, and the country weights, $X_{t}$.

As these variance components show, the determinants of the minimum variance portfolio depend largely upon two sets of variables. The first set is the market weighted parameters, $\widetilde{\mathbf{b}}_{t}^{u}$ and $\widehat{\boldsymbol{\beta}}_{t}^{L}$. The second set of variables is the residual variances for country returns, $\Gamma_{t}$, and the company returns, $\Gamma_{t}$. We report these estimates below for each set of portfolios considered.

\subsection{Results Assuming Less Restrictive Asset Menu}

We begin by considering our most general menu of assets available to the US investor: the US market, the portfolio of foreign companies listed in the US in 2004, and the portfolio of foreign market returns for the home markets of those countries. Clearly, the foreign companies are investable in 2004 since these stocks are traded on the two major US exchanges, NYSE and NASDAQ. However, we are also interested in analyzing how the diversification patterns of these stocks have changed 
over time.

Therefore, to construct our portfolio of foreign companies in the US, we need to take a stand on when the stocks are accessible for investment by US investors. Once again, we evaluate two extremes. At one extreme, we assume that US investors only have access to foreign companies when they become listed on the exchange. However, these securities may be accessible to investors well before this date. Although the stocks are not listed in the US exchanges, the listing on other overseas markets or over-the-counter markets may make the investment readily available even to small investors. Therefore, on the other extreme, we assume that US investors have access since inception to the foreign companies that become listed in the US.

Considering these extremes has two main advantages. First, it allows us to analyze the differences in diversification potential between the set of foreign companies that are listed on the exchange and those that are not yet listed. Second, the two extremes bracket the more realistic intermediate case.

\subsubsection{Assuming foreign companies become investable upon local market listing}

Figures 3 plot the parameter estimates used to determine the portfolio allocation assuming investors have access to the foreign company investments as soon as they are listed in local markets. As noted above, changes in the US returns affect foreign companies according to their factor loadings:

$b^{i u} \equiv \beta^{i \ell} \beta^{\ell}+\beta^{i u}$ where $\beta^{i u}$ is the beta of each foreign company on its local market, $\beta^{\ell}$ is the beta of the home market return on the US market, and $\beta^{i u}$ is the beta of the foreign company on the US market. As Figure 3a shows, the beta on the local market is relatively unchanged over time at around 0.8. However, there is a significant increase over time in both the betas of the country returns and the foreign companies on the US, $\beta^{\ell}$ and $\beta^{i u}$, respectively. As a result, the combined effect is a strong increase in betas against the US, a relationship that proves important for the 
portfolio allocations below.

Figure $3 \mathrm{~b}$ depicts the residual variance for both the foreign country market returns $r^{L}$ and the foreign company returns $r^{F}$. The perceived residual variances for both portfolios increase sharply in the wake of the 1987 crash and then decline through the late 1990s.

The bottom panel of Figure 3 also demonstrates the trend toward inclusion of foreign markets and foreign stocks based solely on availability of those stocks in local markets. The proportion of foreign companies that is available in the US by 2004 become available in their local markets rather gradually. For the 1970s and 1980s, only about 20 to $30 \%$ of these stocks are included in the foreign company portfolio returns, $r^{F}$. However, in the 1990s, the dimension of this portfolio increases quickly so that by 2000 , almost $100 \%$ of the foreign companies are included. The country representation of these stocks follows a more accelerated pace. By 1989, about $50 \%$ of the countries are represented by companies that are accessible in the US. But this proportion increases dramatically so that by 1995 almost 100\% of the countries with listings by 2004 are included.

Figure 4 shows the impact of these parameters and variances on the minimum variance portfolio allocations for the less restrictive set of investment assets. Through the 1980s, investment in foreign securities provides a useful hedge for the US market. The combined betas of the foreign market indices are less than one and even the sharp increase in the residuals after 1987 does not diminish the attractiveness of foreign investment. However, beginning in the 1990s, the increasing betas of foreign market indices and foreign companies both push down the desired allocation in foreign assets. Interestingly, the pattern of desired allocation into foreign companies in the US tends to mirror that of foreign markets. 


\subsubsection{Assuming foreign companies become investable upon U.S. market listing}

While this view of foreign company accessibility is one extreme, it is likely to overstate this accessibility. Figures 5 depict the parameters for the foreign company portfolio when the portfolio is only comprised of companies that have been listed in the US. Comparing the bottom of Figure 5 with the bottom of Figure 3 shows that the rate of inclusion of foreign companies is much more gradual in this case. The number of foreign companies is not 50\% of its total until about 1997 and does not get close to $100 \%$ until around 2004. Moreover the number countries represented increases more slowly. Until 1987 , less than $20 \%$ of the countries are included. The number increases rapidly until 1998 and plateaus at about $80 \%$ until shortly before 2004 .

The parameters and residuals in Figure $5 \mathrm{a}$ and $5 \mathrm{~b}$ reflect this more restricted portfolio set. Unlike the estimates assuming investability since inception of the foreign companies, the parameters of this set remain relatively flat until 2001 and only increase thereafter. The residuals display a different pattern as well, with a more muted increase following the 1987 stock market crash.

Nevertheless, the general patterns of the two sets of foreign company portfolios are similar. As such, the minimum variance portfolio allocations for the less restrictive menu of assets including investments into foreign indices appear relatively similar (not shown). In the next section, we examine more carefully the differences between these two portfolios, but do so under the more conservative scenario that investors cannot hold foreign market indices.

\subsection{Results Assuming More Restrictive Asset Menu}

We next consider the minimum variance allocations under the assumption that the US investor only invests in foreign stocks that become cross-listed in the US. In other words, the portfolio menu is the more restrictive $r^{P}=\left\{r^{u}, r^{F}\right\}$. As noted above, one of the key determinants in this simple twoasset allocation is the covariance between these returns, $\sigma_{U}^{2} \widetilde{b}_{t}^{u}$. Figure 6 plots this covariance over 
time for both the foreign companies listed in the US compared to the foreign companies including those not yet listed. The picture shows that the portfolio of foreign companies listed in the US always has a higher covariance with the US market than the portfolio of those listed in the foreign market.

This relationship carries over to the minimum variance allocations plots in Figure 7A. Until the two portfolios converge in 2004, the US investor would choose to put more of his wealth into the portfolio that includes foreign companies that are not yet listed in the US, than the portfolio of cross-listed foreign companies only. Interestingly, in response to the financial crises of the 2000s, the minimum variance strategy for both portfolios is to short foreign companies. As Figures $3 \mathrm{~A}$ and 5A show, the betas for both portfolios on the US market increase significantly after 2004. The combined direct US beta and indirect US beta through the local market increase to almost 1.6 during this period. As a result, an investor who wants to minimize risk wants to go short this security in order to hedge the US market risk.

Figure 7B show the gains from diversification from the two different portfolios. The portfolio including foreign companies not yet listed in the US provides greater variance reduction throughout the sample. When assuming only long positions in the foreign assets, the variance peaks at around a $4.5 \%$ variance reduction in the 1970s. Allowing for short positions in the 2000 s would imply an even greater variance reduction above $5 \%$.

\section{Alternative Specifications}

We now consider the effects of allowing for alternative specifications along several dimensions: (1) more frequent changes; (2) industry risk; and (3) more gradual parameter shifts. 


\subsection{More frequent parameter changes}

For our analysis so far, we have allowed for breaks that partition subsamples into no less than $15 \%$ of the sample, according to the "trimming" parameter $\varepsilon$ defined by Bai and Perron (2003a,b). As described above, we took this approach because finer partitions of the sample can potentially lead to finding too many breaks. Moreover, this minimum subsample was found to be most reliable in their Monte Carlo tests.

The recent financial crisis may create a problem with using a higher trimming parameter, $\varepsilon$. If stock returns become more correlated at the time of a crisis as argued by Longin and Solnik (2001), then the crisis may have generated a break in parameters nearer 2007 . However, if $15 \%$ of the sample is 5 years as it would be for a series beginning in about 1980, the break would show up in the estimates around 2002. If so, our analysis would be biased toward earlier break date estimation and may therefore affect the variance reduction gains measured earlier.

To address this issue, we estimated all parameters and break dates assuming a finer trimming parameter of $\varepsilon=5 \%$ of the sample. Thus, for country returns, we first generated the set of breakdates $\left\{T_{\tau}^{\ell}\right\}$ and parameter estimates $\left\{\widehat{\alpha}_{\tau}^{\ell}, \widehat{\beta}_{\tau}^{\ell}, \widehat{u}_{t, \tau}^{\ell}\right\}$ and residuals $\widehat{u}_{t, \tau}^{\ell}$ for each interval $\tau=$ $1, \ldots, \widehat{m}^{\ell}+1$ for country $\ell$. Second, using the country-level regressions, we then estimated the company-level break-dates and the parameter estimates $\left\{\alpha_{\varsigma}^{i \ell}, \beta_{\varsigma}^{i \ell}, \beta_{\varsigma}^{i u}\right\}$ and residuals $\widehat{e}_{t, \varsigma}^{i \ell}$ for each interval $\varsigma=1, \ldots, \widehat{n}^{i}+1$ for each company $i$. Consistent with our expectations, we found slightly more breaks and the last break date moves later than 2004 .

To examine the implications of these estimates, we recalculated the portfolio analysis for the typical US investor. In general, our results are quite similar with the exception that the shift toward higher betas occurs later in the 2000s. As a result, the variance reduction attainable from shorting foreign stocks occurs further into the financial crisis and the diversification gains are attenuated.

Figure 8 depicts a comparison between our new results for the shorter trimming parameter, 
$\varepsilon=5 \%$, and our prior results with the longer trimming parameter, $\varepsilon=15 \%$. The figure depicts the portfolio menu of foreign companies in the US assuming access only to cross-listed stocks. The result for the other portfolio menu is similar. As Figure $8 \mathrm{~A}$ shows, the pattern of allocation into foreign stocks are very similar over time. When the trimming parameter is $5 \%$ of the sample, the minimum variance investor tends to hold slightly less foreign company stocks than for the $15 \%$ case. For most of the period, the allocations do not imply much differentiation in variance reduction. However, the slight allocation difference is reflected in bigger diversification gains in the early 2000s since the $15 \%$ \& investor perceives the coming increase in correlations earlier than the $5 \% \varepsilon$ investor.

Overall, the results here suggest that our overall results are robust to allowing for more frequent breaks. While the dating of the breaks at the end of the sample must be viewed with caution, the overall implications for pattern of variance reduction are similar.

\subsection{Industry risk factors}

The analysis in this paper so far has focused upon a two factor model of world and local effects. However, our estimated residual risk may be driven by omitted variables that could affect the shifts in parameters over time. In particular, Bekaert, Hodrick and Zhang (2009) have recently found that multiple factors are needed to explain international stock returns more generally. Also, Brooks and Del Negro (2005) and Carrieri, Errunza, and Sarkissian (2006) have find that industry risks are important in explaining in international stock returns.

To examine the effects of industry risk, we augment the foreign stock level relationship in equation (15) to include an industry factor captured by the return on a market-weighted portfolio of firms within the industry. We then test this model for breaks using the industry portfolios for each of the foreign stocks through 2004 (not shown). We find that the pattern for the number of breaks is roughly the same as in the two factor model. Moreover, we find that while the timing 
of breaks differ somewhat, the implications for diversification are similar to our base model. The residual variances differ between the two factor and three factor model during the early period before 1988. However, after this point, the estimates are virtually identical for the rest of the sample. As a result, the implied portfolio allocation in foreign stocks is essentially unchanged for the post 1988 sample.

Overall, therefore, the general qualitative results for our base two factor framework appear robust to the inclusion of industry effects.

\subsection{Gradual parameter shifts}

The analysis above has focused upon a model with discrete shifts in the parameters. The strongest evidence in breaks occurred at the country level and these breaks were used to condition possible foreign stock market breaks. To keep with the standard factor model approach, we have nested the model within a framework that implied abrupt parameter shifts. On the other hand, it seems likely that at least some of the changes are more gradual, perhaps evolving over time until the changes are picked up by the filter as a shift.

Although our approach can encompass more gradual changes, the risk-reduction thought experiment in this section has treated the changes as discrete within a year window. This restriction raises the question of whether the timing of shifts will be shifted forward or later. To consider

this possibility, we examine a variation of the model proposed by Bai and Perron (2003a) in which the parameters are fixed yet the left hand side variable is auto-correlated. We estimate this model for the country returns through 2004 for the local market model in equation (8) and find that the standard errors of the breaks are generally wider than the abrupt break model in Figure 1 (not shown). However, most of the estimated breaks with the based model occur within the confidence interval of the gradual break model. The results suggest that a more gradual adjustment model 
would imply similar timing to our base model.

\section{Conclusions}

The potential gains from foreign diversification have a long history in the field of financial economics. The more recent integration of financial markets through cross-listed stocks has provided another avenue for this diversification, typically with much lower costs than investing directly in foreign markets.

In this paper, we examine the diversification potential of these companies with an econometric methodology that allows, but does not require, the sensitivity against the US to change over time. We estimate the sensitivities of each foreign company on the home and foreign stock market return, finding that both the betas and correlations of the foreign companies on the US market increase over time. Furthermore, these betas and correlations are higher after cross-listing than before cross-listing.

Using our panel of foreign company parameter estimates, we examine the economic importance of the changes over time to a representative US investor. Consistent with Errunza, Hogan, and Hung (1999) who found that domestically traded portfolios that include cross-listed stocks span foreign markets, our estimates imply that the time-variation of minimum variance allocation into foreign companies tends to mimic the allocation into foreign market returns. Thus, foreign companies in the US provide an opportunity to invest in foreign markets without directly going to those markets.

Strikingly, our estimates also imply that the co-movement of foreign companies to the US market has increased over time. This relationship arises both directly through foreign company betas on the US market and indirectly because the betas of their home markets have increased against the US market. Correspondingly, the portfolio allocation into these companies that would minimize the variance has declined over time. Indeed, during the recent financial crisis, the portfolio variance 
would decline only if the foreign stocks could be shorted.

To understand the diversification potential of cross-listed stocks compared to non-cross-listed stocks, we also analyze the difference between firms that are listed in the US and firms that have not yet listed in the US. While both portfolios of foreign stocks reduce the variability of risk to the US investor, the set that includes foreign companies that have not yet listed in the US provide a greater risk reduction by as much as three times that of the cross-listed stocks over some periods. These results suggest that the diversification gains attainable with foreign companies in the US diminish after cross-listing.

As a by-product of our investigation, we developed a framework based upon Bai and Perron (1998) to test for and estimate shifts in the sensitivity of individual foreign companies against the US. While this paper represents a first attempt to analyze firm-level behavior using this framework, our methodology provides a framework that could be used to address other interesting possibilities. 


\section{REFERENCES}

Andrews, Donald W K, "Heteroskedasticity and Autocorrelation Consistent Covariance Matrix Estimation," Econometrica, 59:3, May 1991, pp. 817-58.

Bai, Jushan; Perron, Pierre, "Estimating and Testing Linear Models with Multiple Structural Changes," Econometrica, 66:1, January 1998, pp. 47-78.

Bai, Jushan; Perron, Pierre, "Computation and Analysis of Multiple Structural Change Models," Journal of Applied Econometrics, 18:1, Jan.-Feb. 2003a, pp. 1-22.

Bai, Jushan; Perron, Pierre, "Critical Values for Multiple Structural Change Tests," Econometrics Journal, 6:1, 2003b, pp. 72-78.

Baruch, Shmuel; Saar, Gideon. "Asset Returns and the Listing Choice of Firms," Review of Financial Studies, 22:6, June 2009, pp. 2239-2274.

Bartram, Sohnke; Griffin, John; and Ng, David. "How Important Is Foreign Ownership in International Stock Returns?" Cornell University Working Paper, 2012.

Bekaert, Geert; Harvey, Campbell R; "Time-Varying World Market Integration," Journal of Finance, 50:2, June 1995, pp. 403-44.

Bekaert, Geert; Harvey, Campbell R, "Emerging Equity Market Volatility,” Journal of Financial Economics, 43:1, January 1997, pp. 29-77.

Bekaert, Geert; Harvey, Campbell R, "Foreign Speculators and Emerging Equity Markets," Journal of Finance, 55:2, April 2000, pp. 565-613.

Bekaert, Geert; Harvey, Campbell R; Lumsdaine, Robin L., "Dating the Integration of World Equity Markets," Journal of Financial Economics, 65:2, August 2002, pp. 203-47. 
Bekaert, G; Hodrick, R., and Zhang, L., "International Stock Return Comovements," Journal of Finance, 64:6, December 2009, pp. 2591-2626.

Black, F. and R. Litterman, "Global Portfolio Optimization," Financial Analysts Journal Sept./Oct. 1992, pp. 28-43.

Bonser-Neal, Catherine; Brauer, Greggory; Neal, Robert; Wheatley, Simon; "International Investment Restrictions and Closed-End Country Fund Prices," Journal of Finance, 45:2, June 1990, pp. 523-47.

Britten-Jones, Mark."The Sampling Error in Estimates of Mean-Variance Efficient Portfolio Weights," Journal of Finance, 54:2 Apr 1999, pp.655-671

Brooks, Robin; Del Negro, Marco. "Country versus Region Effects in International Stock Returns." Journal of Portfolio Management, 2005, 31:4, pp. 67-72.

Campbell, John Y; Lo, Andrew W; MacKinlay, A Craig. The econometrics of financial markets, Princeton: Princeton University Press, 1997.

Carrieri, Francesca; Errunza, Vihang; Sarkissian, Sergei. "The Dynamics of Geographic versus Sectoral Diversification: Is there a Link to the Real Economy?" Weiss Center Working Paper \#06-04, March 2006.

Doidge, Craig; Karolyi, G. Andrew; Stulz, Rene' M. "Why Are Foreign Firms Listed In the U.S. Worth More?" Journal of Financial Economics, 2004, 71:2, pp.205-238.

Doidge, Craig; Karolyi, G. Andrew; Stulz, Rene' M. "The Valuation Premium for Non-US Stocks Listed in U.S. Markets," NYSE Working Paper \#05-01, September 2005.

Dumas, Bernard; Solnik, Bruno, "The World Price of Foreign Exchange Risk," Journal of Finance, 50:2, June 1995, pp. 445-79. 
Errunza, Vihung; K. Hogan and M.W. Hung, "Can the Gains from International Diversification be Achieved Without Trading Abroad?" Journal of Finance, 1999, 54, pp. 2075-2107.

Foerster, Stephen; and G. Andrew Karolyi; "The Effects of Market Segmentation and Investor Recognition on Asset Prices: Evidence from Foreign Stocks Listing in the U.S.," Journal of Finance 54, 1999, pp. 981-1014.

Henry, Peter Blair; "Stock Market Liberalization, Economic Reform, and Emerging Market Equity Prices," Journal of Finance, 55:2, April 2000, pp. 529-64.

Henry, Peter Blair, "Capital-Account Liberalization, the Cost of Capital, and Economic Growth," American Economic Review, 93:2, May 2003, pp. 91-96.

Karolyi, G Andrew, "The World of Cross-Listings and Cross-Listings of the World: Challenging Conventional Wisdom," Review of Finance, 10:1, 2006, pp. 99-152.

Karolyi, G. Andrew; Wu, Ying. "The Role of Investability Restrictions on Size, Value, and Momentum in International Stock Returns," Johnson School University of Cornell Working Paper, 2012

Lewis, Karen K. "Trying to Explain Home Bias in Equities and Consumption," Journal of Economic Literature, June 1999, 37:2, pp. 571-608.

Liu, Edith "Diversifying Credit Risk with International Corporate Bonds", Cornell University Working Paper, 2012.

Longin, Francois; Solnik, Bruno, "Extreme Correlation of International Equity Markets," Journal of Finance, 56: 2, April 2001, pp. 649-676.

Pastor, Lubos, "Portfolio Selection and Asset Pricing Models," Journal of Finance, 55:1, February 2000, pp. 179-223. 
Sarkissian, Sergei; Schill, Michael J. "Are There Permanent Valuation Gains to Overseas Listing?" Review of Financial Studies, 22:1 Jan 2009, pp. 371-412

Solnik, Bruno H., "The International Pricing of Risk: An Empirical Investigation of the World Capital Market Structure," Journal of Finance, 29:2 May 1974, pp.365-378

Stehle, Richard E. "An Empirical Test of the Alternative Hypotheses of National and International Pricing of Risky Assets," Journal of Finance, 32:2 May 1977, pp. 493-502.

Stock, James H. "Unit Roots, Structural Breaks and Trends," Handbook of econometrics 4, 1994, pp. 2739-2841.

White, Halbert, "Heteroskedasticity-Consistent Covariance Matrix Estimator and a Direct Test for Heteroskedasticity," Econometrica, 48:4, May 1980, pp. 817-38. 


\section{Appendices}

\section{Appendix A: Data Description}

The data for the individual company stock returns were collected and cross-checked from the websites of the NYSE and NASDAQ and three ADR custodian depositaries: JP Morgan, Citibank, and Bank of New York. Using these sources, we selected all companies that were trading on NYSE and NASDAQ in July 2004. We then extracted the weekly Total Return Index series for each company from January 1970 to October 2009. Companies with less than 60 observations were excluded. For each of these companies, we compiled the Data Stream market return index from their home market. Table 1 in the text reports these countries. To calculate excess returns, the weekly T-bill rate from Ken French's data set was subtracted from each stock return.

\section{Appendix B: Comparison on Market Index Returns to Bekaert-Harvey-Lumsdaine}

In Table 2 and Figure 1, we report break-tests of country market indices against the US market index returns. Similarly, Bekaert, Harvey, and Lumsdaine (2002) BHL estimate break tests for market return indices. However, the purpose of the BHL study is to date endogenous liberalization break dates in aggregate macro-level time series. As such their focus is different from our analysis on the diversification potential of individual stock returns. Nevertheless, it is interesting to consider the relationship between the two sets of studies.

Table A summarizes the break dates estimates from the BHL study in the first two columns. BHL consider both a break in the mean in column A and a break in all the parameters in column B. Since the question addressed by BHL concerns liberalization, they study emerging markets exclusively. On the other hand, in this paper we examine emerging markets only to the extent that they have stocks listed in the US. As a result, the set of countries we have in common with BHL is a smaller set of 14 countries. 
Another difference between our studies is that BHL has a different sample period. While Bekaert and Harvey (2000) report that the samples differ by country, the maximum possible sample period for any country is from January 1976 to December 1995. By contrast, our inclusion of countries depends upon whether a company from the home country is represented on the US exchange. The third column summarizes the maximum number of overlapping years in the two studies. These range from 1.5 for Brazil to 23 years for Mexico and Venezuela.

The break date estimates using the $\sup (\mathrm{F})$ tests are reported in the last six columns for the case where the minimum subsample partition allowed is $15 \%$ and $5 \%$ of the sample, respectively. Several interesting features arise from the comparison. First, and least surprisingly, for the countries where there is little overlap in sample periods, the estimated breakdates with the $\sup (\mathrm{F})$ tests occur later than the BHL estimates. For example, the median BHL estimates for breaks in Argentina and Brazil occur in the mid to late 1980s, though these estimates are not significant. On the other hand, using the later sample, we find strong evidence of breaks in 1999 and 2002, closer to the Argentine and Brazilian crises periods. Second, for some countries where BHL found strong evidence of breaks before our sample, we do not find evidence of later breaks. For example, BHL estimate break dates for the Philippines and Indonesia in 1987 and 1991, respectively, but with our later samples, we find no evidence of further breaks. Third, to allow for the possibility that the minimum subsample restriction is binding for some of our countries with shorter samples, we also estimate the model allowing for a shorter restriction of $5 \%$ of the sample. For Brazil, Chile, Turkey, and Taiwan, we do indeed find evidence of finer sample partitions. Finally, for some countries when we have a similar sample period, our estimated break dates are relatively close. For example, for Venezuela, both BHL and our estimates suggest a break in the early 1990s.

Overall, while our sample periods and independent variables differ from BHL, our qualitative results are similar where they overlap. 


\section{Appendix C: Minimum Variance Portfolio Model}

The estimates of the model were used to evaluate the decision for a representative US investor who is deciding on how much to allocate into foreign stock portfolios. Under the assumptions of i.i.d., an investor who minimizes the variance of expected returns will choose to hold the minimum variance portfolio given by equation (7) in the text. To examine the decision of the investor over time, we evaluate the conditional version given as:

$$
\omega_{t}=\frac{V_{t}^{-1} \iota}{\iota^{\prime} V_{t}^{-1} \iota}
$$

where $t$ subscripts refer to the information set at time $t$. Thus, $V_{t}$ is the conditional variancecovariance matrix of returns.

Below we describe the moments for the two portfolio menus described in the text: (a) the two-asset model implied by the more restrictive portfolio menu of the US and cross-listed stocks; and (b) the three asset model implied by the least restrictive portfolio menu of the US, cross-listed stocks, and foreign market indices.

\section{Two Asset Model}

For the two asset model, the investor chooses between a market-weighted portfolio of cross-listed foreign company returns and the US market. In this case,

$$
\mathbf{r}_{t}^{p} \equiv\left[r_{t}^{u}, r_{t}^{F}\right]=\left[r_{t}^{u}, Z_{t}^{\prime} \mathbf{r}_{t}^{i}\right]
$$

Where $\mathbf{r}_{t}^{i}$ is an $N \times 1$ vector of the cross-listed foreign company returns at time $t, Z_{t}$ is an $N \times 1$ vector of the shares of market weights of the foreign stocks as a proportion of the market weight of all the foreign stocks in the portfolio at time $t$. 
Note that the returns for each element in $\mathbf{r}_{t}^{i}$ are given by the firm level process in the text, rewritten here as:

$$
r_{t}^{i \ell}=\Xi\left(\kappa_{\varsigma}\right)\left[\alpha_{\varsigma}^{i \ell}+\beta_{\varsigma}^{i \ell} r_{t}^{\ell}+\beta_{\varsigma}^{i u} r_{t}^{u}+e_{\varsigma, t}^{i \ell}\right], \text { for } i=1, \ldots, N ; \varsigma=1, \ldots, n^{i}+1
$$

where $\Xi\left(\kappa_{\varsigma}\right)$ is an indicator function for the event that time t is within a set of time.

However, the local market returns also depend upon the US return according to:

$$
r_{t}^{\ell}=I\left(T_{\tau}\right)\left[\alpha_{\tau}^{\ell}+\beta_{\tau}^{\ell} r_{t}^{u}+u_{t, \tau}^{\ell}\right], \text { for } \ell=1, \ldots, L ; \tau=1, \ldots, m+1
$$

where $I\left(T_{\tau}\right)$ is an indicator function that time is within a set of time intervals $T_{\tau}$ for $\tau=1, \ldots, m+1$.

We now redefine the parameter vector by mapping the set of parameter vectors in both time subsets $T_{\tau}$ and $\kappa_{\varsigma}$ into parameters at each date $t$. Thus, $\delta_{t}$ represents the mapping of parameters for countries within their time subsets $T_{\tau}$ into the time domain $t$ and for stocks within their time subsets $\kappa_{\varsigma}$. For example, the country-level parameters are defined over time as:

$$
\delta_{t}=\left\{\delta_{t} \mid t=I^{-1}\left(T_{\tau}\right) ; \tau=1, \ldots, m+1\right\}
$$

Then substituting (A4) into (A3), the company returns can be rewritten:

$$
r_{t}^{i \ell}=a_{t}^{i \ell}+b_{t}^{i \ell} r_{t}^{u}+\varepsilon_{t}^{i \ell}
$$


where

$$
\begin{aligned}
& a_{t}^{i \ell}=\alpha^{i \ell}+\beta^{i \ell} \alpha_{\tau}^{\ell} \\
& b_{t}^{i \ell}=\beta^{i \ell} \beta_{\tau}^{\ell}+\beta^{i u} \\
& \varepsilon_{t}^{i \ell} \equiv \beta^{i \ell} u_{t, \tau}^{\ell}+e_{t}^{i \ell}
\end{aligned}
$$

Then the variance-covariance matrix of the portfolio vector of returns, $r^{p}$, is:

$$
V_{t}=\left[\begin{array}{cc}
\sigma_{U}^{2} & \sigma_{U}^{2} \mathbf{Z}_{t}^{\prime} \mathbf{b}_{t}^{U} \\
\sigma_{U}^{2} \mathbf{Z}_{t}^{\prime} \mathbf{b}_{t}^{U} & \sigma_{U}^{2} \mathbf{Z}_{t}^{\prime} \mathbf{b}_{t}^{u} \mathbf{b}_{t}^{u \prime} \mathbf{Z}_{t}+\left(\mathbf{Z}_{t} \cdot \widetilde{\boldsymbol{\beta}}_{t}^{L}\right)^{\prime} \Gamma_{t}\left(\mathbf{Z}_{t} \cdot \widetilde{\boldsymbol{\beta}}_{t}^{L}\right)+\mathbf{Z}_{t}^{\prime} \Omega_{t} \mathbf{Z}_{t}
\end{array}\right]
$$

Where $\mathbf{b}_{t}^{U}$ is the $N \times 1$ parameter vector with typical element $b_{t}^{i \ell}$ and $\boldsymbol{\beta}_{t}^{L}$ is the $N \times 1$ parameter

vector of country market loadings, $\widetilde{\boldsymbol{\beta}}_{t}^{L}$, and where $\cdot$ in the operation $\mathbf{Z}_{t} \cdot \widetilde{\boldsymbol{\beta}}_{t}^{L}$ indicates element by element multiplication. Furthermore, the company residual variance-covariance matrix is given by: $\Omega_{t}=E_{t}\left(\mathbf{e}_{t} \mathbf{e}_{t}^{\prime}\right)=$ for $\mathbf{e}_{t}$ the vector of company return residuals, with typical element, $e_{\tau, t}^{i \ell}$. Similarly, the country residual variance-covariance matrix arrayed by each firm's home country is given by the $L \times L$ matrix: $\quad \widetilde{\Gamma}_{t} \equiv E_{t}\left(\mathbf{u}_{t} \mathbf{u}_{t}^{\prime}\right)$ where $\mathbf{u}_{t}$ is the $L \times 1$ vector of residuals to each company's home market regression on the US market.

In estimating the parameters and variances of the model, we did not assume homoskedasticity of the residuals. However, for the portfolio model, we assume that the agent assume variances will be constant over the next year. Moroever, the model treats the portfolio variance as changing over time in response to the evolution of the parameters $\delta$ and weights $Z$. Note that in the off-diagonal terms in (A6), we have used the fact that: $E_{t}\left(\mathbf{u}_{t} r_{t}^{u}\right)=0$ by construction in estimating equation (3). 


\section{Three Asset Model}

For the three asset model, the investor chooses between a market-weighted portfolio of foreign stocks traded in the US, the portfolio of foreign market indices, and the US market. In this case, we redefine the return vector to be:

$$
\mathbf{r}_{t}^{p} \equiv\left[r_{t}^{u}, r_{t}^{F}, r_{t}^{L}\right]=\left[r_{t}^{u}, \mathbf{Z}_{t}^{\prime} \mathbf{r}_{t}^{i}, \mathbf{X}_{t}^{\prime} \mathbf{r}_{t}^{\ell}\right]
$$

where $\mathbf{r}_{t}^{\ell}$ is an $L \times 1$ vector of foreign market returns at time $t, \mathbf{X}_{t}$ is an $L \times 1$ vector of the market weights of the foreign market indices as a proportion of the total set of foreign market indices with home companies listed in the US and where the other parameters are as defined above.

Then the variance of the three-asset version of the model can be written:

$$
V_{t}=\left[\begin{array}{ccc}
\sigma_{U}^{2} & \sigma_{U}^{2} \mathbf{Z}_{t}^{\prime} \mathbf{b}_{t}^{U} & \sigma_{U}^{2} \mathbf{X}_{t}^{\prime} \widehat{\boldsymbol{\beta}}_{t}^{L} \\
\sigma_{U}^{2} \mathbf{Z}_{t}^{\prime} \mathbf{b}_{t}^{U} & \sigma_{U}^{2} \mathbf{Z}_{t}^{\prime} \mathbf{b}_{t}^{u} \mathbf{b}_{t}^{u \prime} \mathbf{Z}_{t}+\left(\mathbf{Z}_{t} \cdot \widetilde{\boldsymbol{\beta}}_{t}^{L}\right)^{\prime} \Gamma_{t}\left(\mathbf{Z}_{t} \cdot \widetilde{\boldsymbol{\beta}}_{t}^{L}\right)+\mathbf{Z}_{t}^{\prime} \Omega_{t} \mathbf{Z}_{t} & \sigma_{U}^{2} \mathbf{Z}_{t}^{\prime} \mathbf{b}_{t}^{u} \widehat{\boldsymbol{\beta}}_{t}^{L \prime} \mathbf{X}_{t}+\left(\mathbf{Z}_{t} \cdot \widetilde{\boldsymbol{\beta}}_{t}^{\ell}\right) \widetilde{\widetilde{\Gamma}}_{t} \mathbf{X}_{t} \\
\sigma_{U}^{2} \mathbf{X}_{t}^{\prime} \widehat{\boldsymbol{\beta}}_{t}^{L} & \sigma_{U}^{2} \mathbf{Z}_{t}^{\prime} \mathbf{b}_{t}^{u} \widehat{\boldsymbol{\beta}}_{t}^{L \prime} \mathbf{X}_{t}+\left(\mathbf{Z}_{t} \cdot \widetilde{\boldsymbol{\beta}}_{t}^{\ell}\right) \widehat{\widetilde{\Gamma}}_{t} \mathbf{X}_{t} & \sigma_{U}^{2} \mathbf{X}_{t}^{\prime} \widehat{\boldsymbol{\beta}}_{t}^{L} \widehat{\boldsymbol{\beta}}_{t}^{L} \mathbf{X}_{t}+X_{t}^{\prime} \widehat{\Gamma}_{t} X_{t}
\end{array}\right]
$$

where now we have the additional terms of the $L \times L$ variance-covariance matrix of country residuals $\widehat{\Gamma}_{t} \equiv E_{t}\left(\mathbf{u}_{t} \mathbf{u}_{t}^{\prime}\right)$ where $\mathbf{u}_{t}$ is the $L \times 1$ vector of residuals to each company's home market regression on the US market and the $N \times L$ covariance matrix of country residuals $\widetilde{\Gamma}_{t} \equiv E_{t}\left(\widetilde{\mathbf{u}}_{t} \mathbf{u}_{t}^{\prime}\right)$ and the $L \times 1$ vector of country betas, $\widetilde{\boldsymbol{\beta}}_{t}^{\ell}$. 


\section{Table 1: Summary Statistics for Foreign Companies Listed in US Exchanges}

\begin{tabular}{|c|c|c|c|c|}
\hline \multicolumn{5}{|c|}{ Panel A: Summary Information about Foreign Firms Listed by Exchange and Tot } \\
\hline Stock Exchange & $\begin{array}{c}\text { No. of } \\
\text { Firms }\end{array}$ & $\begin{array}{c}\text { No. of } \\
\text { Countries }\end{array}$ & $\begin{array}{c}\text { No. of } \\
\text { Industries }\end{array}$ & $\begin{array}{c}\text { Average Firm } \\
\text { Observations }\end{array}$ \\
\hline NYSE & 380 & 39 & 47 & 1092 \\
\hline NASDAQ & 196 & 28 & 40 & 862 \\
\hline Both Exchanges & 576 & 42 & 47 & 977 \\
\hline \multicolumn{5}{|c|}{ Panel B: Summary Information about Foreign Firms Listed by Country } \\
\hline Country & $\begin{array}{c}\text { Market Begin } \\
\text { Data }\end{array}$ & $\begin{array}{c}\text { No. of Firms- } \\
\text { NYSE }\end{array}$ & $\begin{array}{c}\text { No. of Firms } \\
\text { NASDAQ }\end{array}$ & $\begin{array}{c}\text { Average Firm } \\
\text { Observations }\end{array}$ \\
\hline Argentina & Aug 6, 1993 & 9 & 3 & 733 \\
\hline Australia & Jan 5, 1973 & 12 & 8 & 1324 \\
\hline Austria & Jan 5, 1973 & 2 & 0 & 466 \\
\hline Belgium & Jan 5, 1973 & 1 & 0 & 1917 \\
\hline Brazil & Jul 8, 1994 & 35 & 1 & 676 \\
\hline Canada & Jan 5, 1973 & 57 & 63 & 1009 \\
\hline Chile & Jul 7, 1989 & 17 & 0 & 457 \\
\hline China & Jul 30, 1993 & 12 & 5 & 527 \\
\hline Colombia & Mar 13, 1992 & 1 & 0 & 764 \\
\hline Denmark & Jan 5, 1973 & 2 & 2 & 1401 \\
\hline Finland & Mar 25, 1988 & 4 & 0 & 1055 \\
\hline France & Jan 5, 1973 & 22 & 10 & 921 \\
\hline Germany & Jan 5, 1973 & 15 & 3 & 869 \\
\hline Greece & Jan 5, 1990 & 3 & 1 & 760 \\
\hline Hong Kong & Jan 5, 1973 & 7 & 5 & 579 \\
\hline Hungary & Jun 21,1991 & 1 & 0 & 620 \\
\hline India & Jan 5, 1990 & 8 & 3 & 772 \\
\hline
\end{tabular}


Table 1: Summary Statistics for Foreign Companies

Listed in US Exchanges (cont.)

\begin{tabular}{|c|c|c|c|c|}
\hline Country & $\begin{array}{c}\text { Market Index } \\
\text { Begin Date }\end{array}$ & $\begin{array}{c}\text { No.of Firms: } \\
\text { NYSE }\end{array}$ & $\begin{array}{c}\text { No. of Firms: } \\
\text { NASDAQ }\end{array}$ & $\begin{array}{c}\text { Average Firm } \\
\text { Observations }\end{array}$ \\
\hline Indonesia & Jan 5, 1990 & 2 & 0 & 376 \\
\hline Ireland & Jan 5, 1973 & 3 & 8 & 1348 \\
\hline Israel & Jan 1, 1993 & 2 & 6 & 671 \\
\hline Italy & Jan 5, 1973 & 10 & 0 & 908 \\
\hline Japan & Jan 5, 1973 & 18 & 12 & 1585 \\
\hline Korea & Sep 11, 1987 & 5 & 3 & 708 \\
\hline Luxemburg & Jan 3, 1992 & 2 & 1 & 644 \\
\hline Malaysia & May 12, 1989 & 0 & 1 & 729 \\
\hline Mexico & Jan 5, 1973 & 24 & 2 & 796 \\
\hline Netherland & Jan 8,1988 & 16 & 7 & 1182 \\
\hline New Zealand & Jan 4, 1980 & 1 & 0 & 475 \\
\hline Norway & Jan 7, 1994 & 4 & 3 & 794 \\
\hline Peru & Sep 11, 1987 & 2 & 0 & 947 \\
\hline Philippine & Jan 5, 1990 & 2 & 1 & 411 \\
\hline Portugal & Jun 24,1994 & 3 & 0 & 841 \\
\hline Russia & Jan 5,1973 & 3 & 0 & 641 \\
\hline Singapore & Mar 6, 1987 & 0 & 2 & 511 \\
\hline South Africa & Jan 5, 1973 & 6 & 5 & 1149 \\
\hline Spain & May 6, 1988 & 6 & 1 & 773 \\
\hline Sweden & Jan 8, 1988 & 0 & 7 & 989 \\
\hline Switzerland & Jan 2, 1970 & 10 & 2 & 948 \\
\hline Taiwan & Jan 5, 1990 & 5 & 2 & 793 \\
\hline Turkey & Aug 6, 1993 & 1 & 0 & 483 \\
\hline United Kingdom & Jan 5, 1973 & 46 & 29 & 1160 \\
\hline Venezuela & Jan 5, 1973 & 1 & 0 & 671 \\
\hline
\end{tabular}




\section{Table 2 Summary Statistics on Break Tests}

Panel A reports the proportion of foreign country returns rejecting the hypothesis that there are less than one, two, three and unknown breaks in the regression: $r_{t}^{\ell}=\alpha^{\ell}+\beta^{\ell} r_{t}^{u}+u_{t}^{\ell}$, where $r_{t}^{\ell}$ is the excess return of country $\ell$ 's equity return, $r_{t}^{u}$ is the excess return of the US.

Panel B gives the results of the sequential Sup $(F)$ test.

Panel $\mathrm{C}$ reports means and standard errors of the break dates.

\begin{tabular}{|l|c|c|c|c|c|}
\hline \multicolumn{6}{|c|}{ Panel A: Proportion of Countries Rejecting No Breaks } \\
\hline MSL $^{a}$ & \multicolumn{3}{|c|}{$\begin{array}{l}\text { Sup F test of No Break } \\
\text { vs: }\end{array}$} & \multicolumn{2}{c|}{$\begin{array}{l}\text { Tests of No Break vs } \\
\text { Unknown Number of Breaks }\end{array}$} \\
\hline & $\mathrm{m}=1$ & $\mathrm{~m}=2$ & $\mathrm{~m}=3$ & UD Max & WD Max \\
\hline $10 \%$ & 0.857 & 0.929 & 0.929 & 0.905 & 0.929 \\
\hline $5 \%$ & 0.857 & 0.857 & 0.905 & 0.881 & 0.905 \\
\hline $1 \%$ & 0.810 & 0.810 & 0.857 & 0.833 & 0.786 \\
\hline \multicolumn{6}{|c|}{ Panel B: Distribution of Break Categories } \\
\hline MSL $^{a}$ & $\begin{array}{l}\text { Proportion of } \\
\text { Total Countries }\end{array}$ & Proportional \# of Breaks ${ }^{c}$ over \\
& $\begin{array}{l}\text { Rejecting } \\
\text { Ho: No Breaks }\end{array}$ & 1 Break & 2 Breaks & 3 Breaks \\
\hline $10 \%$ & \multicolumn{6}{|c|}{0.857} & 0.611 & 0.250 & 0.139 \\
\hline $5 \%$ & 0.857 & 0.750 & 0.167 & 0.083 \\
\hline $1 \%$ & \multicolumn{6}{|c|}{0.810} & 0.853 & 0.118 & 0.029 \\
\hline
\end{tabular}

${ }^{a}$ Marginal significance levels for the test of no structural break and the sequential $\sup (\mathrm{F})$ test. ${ }^{b}$ Ratio of the number of countries that reject the test of no structural break over the total number of countries. ${ }^{c}$ Proportion of countries that reject sequential test of a given number of breaks plus one over the number of countries that reject the supF test of no structural break. 
Table 3 Foreign Market Beta Summary Statistics

Estimate means, standard error means, and cross-sectional standard deviations for various market portfolios in the regression: $r_{t}^{\ell}=\alpha^{\ell}+\beta^{\ell} r_{t}^{u}+u_{t}^{\ell}$ where $r_{t}^{\ell}$ is the excess return of country $\ell$ 's equity return, $r_{t}^{u}$ is the excess return of the US market. "Periods" are defined as the interval over which a parameter is stable and do not correspond to the same time periods for all countries.

\begin{tabular}{|c|c|c|c|c|c|}
\hline Portfolio & Estimate & $\begin{array}{c}\text { Period } 1 \\
(\tau=1)\end{array}$ & $\begin{array}{c}\text { Period 2 } \\
\quad(\tau=2)\end{array}$ & $\begin{array}{c}\text { Period } 3 \\
\quad(\tau=3)\end{array}$ & $\begin{array}{c}\text { Period } 4 \\
\quad(\tau=4)\end{array}$ \\
\hline \multicolumn{6}{|c|}{ Panel A: All Countries Market Weighted Vs. Equally Weighted } \\
\hline \multirow{5}{*}{$\begin{array}{l}\text { Market } \\
\text { Weighted }\end{array}$} & $\beta^{\ell}$ Mean & 0.348 & 0.802 & 0.866 & 1.109 \\
\hline & Std Err Mean & 0.047 & 0.049 & 0.039 & 0.038 \\
\hline & $\operatorname{Corr}\left(r^{\ell}, r^{u}\right)$ & 0.198 & 0.355 & 0.436 & .471 \\
\hline & $\beta^{\ell} \mathrm{St}$ Dev & 0.248 & 0.315 & 0.341 & 0.234 \\
\hline & No. of Obs & 42 & 35 & 9 & 2 \\
\hline \multirow{5}{*}{$\begin{array}{l}\text { Equally } \\
\text { Weighted }\end{array}$} & $\beta^{\ell}$ Mean & 0.378 & 0.843 & 0.799 & 0.973 \\
\hline & Std Err Mean & 0.063 & 0.066 & 0.053 & 0.047 \\
\hline & $\operatorname{Corr}\left(r^{\ell}, r^{u}\right)$ & 0.198 & 0.355 & 0.436 & 0.471 \\
\hline & $\beta^{\ell} \mathrm{St}$ Dev & 0.248 & 0.315 & 0.341 & 0.234 \\
\hline & No. of Obs & 42 & 35 & 9 & 2 \\
\hline \multicolumn{6}{|c|}{ Panel B: Market Weighted Developed Vs. Emerging } \\
\hline \multirow{5}{*}{$\begin{array}{l}\text { Market } \\
\text { Weighted }\end{array}$} & $\beta^{\ell}$ Mean & 0.325 & 0.785 & 0.903 & 1.138 \\
\hline & Std Err Mean & 0.041 & 0.044 & 0.035 & 0.037 \\
\hline & $\operatorname{Corr}\left(r^{\ell}, r^{u}\right)$ & 0.195 & 0.361 & 0.474 & 0.479 \\
\hline & $\beta^{\ell} \mathrm{St}$ Dev & 0.171 & 0.272 & 0.167 & 0.000 \\
\hline & No. of Obs & 21 & 21 & 5 & 1 \\
\hline \multirow{5}{*}{$\begin{array}{l}\text { Equally } \\
\text { Weighted }\end{array}$} & $\beta^{\ell}$ Mean & 0.453 & 0.928 & 0.657 & 0.807 \\
\hline & Std Err Mean & 0.074 & 0.085 & 0.064 & 0.057 \\
\hline & $\operatorname{Corr}\left(r^{\ell}, r^{u}\right)$ & 0.208 & 0.309 & 0.223 & 0.384 \\
\hline & $\beta^{\ell} \mathrm{St}$ Dev & 0.297 & 0.379 & 0.387 & 0.000 \\
\hline & No. of Obs & 21 & 14 & 4 & 1 \\
\hline
\end{tabular}


Table 3 Foreign Market Beta Summary Statistics (cont.)

\begin{tabular}{|c|c|c|c|c|c|}
\hline Portfolio & Estimate & $\begin{array}{c}\text { Period } 1 \\
(\tau=1)\end{array}$ & $\begin{array}{c}\text { Period 2 } \\
(\tau=2)\end{array}$ & $\begin{array}{c}\text { Period } 3 \\
\quad(\tau=3)\end{array}$ & $\begin{array}{c}\text { Period } 4 \\
(\tau=4)\end{array}$ \\
\hline \multicolumn{6}{|c|}{ Panel C: Market Weighted by Region } \\
\hline \multirow{5}{*}{ Asia } & $\beta^{\ell}$ Mean & 0.230 & 0.505 & 0.258 & $\mathrm{n} / \mathrm{a}$ \\
\hline & Std Err Mean & 0.063 & 0.045 & 0.055 & $\mathrm{n} / \mathrm{a}$ \\
\hline & $\operatorname{Corr}\left(r^{\ell}, r^{u}\right)$ & 0.104 & 0.285 & 0.127 & $\mathrm{n} / \mathrm{a}$ \\
\hline & $\beta^{\ell} \mathrm{St}$ Dev & 0.267 & 0.221 & 0.000 & $\mathrm{n} / \mathrm{a}$ \\
\hline & No. of Obs & 11 & 6 & 1 & $\mathrm{n} / \mathrm{a}$ \\
\hline \multirow{5}{*}{ Europe } & $\beta^{\ell}$ Mean & 0.380 & 0.894 & 1.028 & $\mathrm{n} / \mathrm{a}$ \\
\hline & Std Err Mean & 0.036 & 0.047 & 0.041 & $\mathrm{n} / \mathrm{a}$ \\
\hline & $\operatorname{Corr}\left(r^{\ell}, r^{u}\right)$ & 0.247 & 0.393 & 0.503 & $\mathrm{n} / \mathrm{a}$ \\
\hline & $\beta^{\ell}$ St Dev & 0.174 & 0.294 & 0.052 & $\mathrm{n} / \mathrm{a}$ \\
\hline & No. of Obs & 18 & 18 & 4 & $\mathrm{n} / \mathrm{a}$ \\
\hline \multirow{5}{*}{$\begin{array}{l}\text { Middle } \\
\text { East \& } \\
\text { Africa }\end{array}$} & $\beta^{\ell}$ Mean & 0.334 & 0.788 & 1.119 & $\mathrm{n} / \mathrm{a}$ \\
\hline & Std Err Mean & 0.065 & 0.082 & 0.073 & $\mathrm{n} / \mathrm{a}$ \\
\hline & $\operatorname{Corr}\left(r^{\ell}, r^{u}\right)$ & 0.174 & 0.220 & 0.323 & $\mathrm{n} / \mathrm{a}$ \\
\hline & $\beta^{\ell} \mathrm{St}$ Dev & 0.245 & 0.422 & 0.000 & $\mathrm{n} / \mathrm{a}$ \\
\hline & No. of Obs & 3 & 2 & 1 & $\mathrm{n} / \mathrm{a}$ \\
\hline \multirow{5}{*}{$\begin{array}{l}\text { North } \\
\text { America }\end{array}$} & $\beta^{\ell}$ Mean & 0.607 & 0.975 & 0.693 & 1.138 \\
\hline & Std Err Mean & 0.043 & 0.051 & 0.025 & 0.037 \\
\hline & $\operatorname{Corr}\left(r^{\ell}, r^{u}\right)$ & 0.239 & 0.323 & 0.424 & 0.479 \\
\hline & $\beta^{\ell} \mathrm{St}$ Dev & 0.178 & 0.284 & 0.000 & 0.000 \\
\hline & No. of Obs & 2 & 2 & 1 & 1 \\
\hline \multirow{5}{*}{ Oceania } & $\beta^{\ell}$ Mean & 0.399 & 1.107 & $\mathrm{n} / \mathrm{a}$ & $\mathrm{n} / \mathrm{a}$ \\
\hline & Std Err Mean & 0.032 & 0.058 & $\mathrm{n} / \mathrm{a}$ & $\mathrm{n} / \mathrm{a}$ \\
\hline & $\operatorname{Corr}\left(r^{\ell}, r^{u}\right)$ & 0.260 & 0.388 & $\mathrm{n} / \mathrm{a}$ & $\mathrm{n} / \mathrm{a}$ \\
\hline & $\beta^{\ell} \mathrm{St}$ Dev & 0.047 & 0.211 & $\mathrm{n} / \mathrm{a}$ & $\mathrm{n} / \mathrm{a}$ \\
\hline & No. of Obs & 2 & 2 & $\mathrm{n} / \mathrm{a}$ & $\mathrm{n} / \mathrm{a}$ \\
\hline \multirow{5}{*}{$\begin{array}{l}\text { South } \\
\text { America }\end{array}$} & $\beta^{\ell}$ Mean & 0.578 & 1.166 & 0.377 & 0.807 \\
\hline & Std Err Mean & 0.087 & 0.083 & 0.060 & 0.057 \\
\hline & $\operatorname{Corr}\left(r^{\ell}, r^{u}\right)$ & 0.203 & 0.404 & 0.176 & 0.384 \\
\hline & $\beta^{\ell} \mathrm{St}$ Dev & 0.412 & 0.509 & 0.160 & 0.000 \\
\hline & No. of Obs & 6 & 5 & 2 & 1 \\
\hline
\end{tabular}




\section{Table 4 Summary Statistics of Foreign Market \\ Breaks and Restrictions on Foreign Firm Pricing}

Panel A reports the number and proportion of foreign stocks listed in the US domiciled in home countries with number of breaks as in Table 2. Panel B reports the number and proportion of the firms that reject the hypothesis that the estimates are stable in the equation system:

$$
\begin{gathered}
r_{t}^{\ell}=\alpha_{\tau}^{\ell}+\beta_{\tau}^{\ell} r_{t}^{U}+u_{t, \tau}^{\ell} \\
r_{t}^{i \ell}=\alpha^{i \ell}+\beta^{i \ell} \alpha_{\tau}^{\ell}+\left(\beta^{i U}+\beta^{i \ell} \beta_{\tau}^{\ell}\right) r_{t}^{U}+\beta^{i \ell} u_{t, \tau}^{\ell}+e_{t}^{i \ell}
\end{gathered}
$$

for $\ell=1, \ldots, L$, the total number of countries, and $\tau=1, \ldots, m^{\ell}$ where $m^{\ell}$ is the estimated number of breaks for country $\ell$. The first equation is the same market equity excess return regression reported in Tables 2 and 3 . The second equation regresses the excess return of firm $i$ from home country $\ell$ on a two factor model of the local market excess return and the US market return. Panel C reports the number

\begin{tabular}{|c|c|c|c|c|}
\hline \multicolumn{5}{|c|}{ Panel A: Firms Decomposed by Country Break Category } \\
\hline Statistic & $\begin{array}{c}\text { One Break } \\
\quad m=1\end{array}$ & $\begin{array}{c}\text { Two Breaks } \\
\mathrm{m}=2\end{array}$ & $\begin{array}{c}\text { Three Breaks } \\
\qquad \mathrm{m}=3\end{array}$ & All \\
\hline Proportion of Firms ${ }^{a}$ & 0.620 & 0.089 & 0.238 & 0.946 \\
\hline No of Firms & 357 & 51 & 137 & 545 \\
\hline \multicolumn{5}{|c|}{ Panel B: Distribution of Break Categories Using Sequential Test } \\
\hline Tests for Breaks & & & & \\
\hline Beyond country level & No Breaks & One Break & Two Breaks & Three Breaks \\
\hline Proportion of Firms ${ }^{a}$ & 0.487 & 0.406 & 0.097 & 0.011 \\
\hline No of Firms & $277^{b}$ & 231 & 55 & 6 \\
\hline \multicolumn{5}{|c|}{ Panel C: Firms Rejecting Parameter Constancy } \\
\hline Null Hypothesis & $\begin{aligned} \text { No Local Effect } & \\
& 0.810 \\
H o: & \beta_{\tau}^{i \ell}=0, \forall \tau\end{aligned}$ & $\begin{array}{c}\text { No US Effect } \\
H o: \beta_{\tau}^{i U}=0, \forall \tau\end{array}$ & $\begin{array}{c}\text { Local Effect } \\
\text { Constant } \\
H o: \beta_{\tau}^{i \ell}=\beta^{i \ell}, \forall \tau\end{array}$ & $\begin{array}{c}\text { World Effect } \\
\text { Constant } \\
H o: \beta_{\tau}^{i U}=\beta^{i U}, \forall \tau\end{array}$ \\
\hline Proportion of Firms ${ }^{a}$ & 0.849 & 0.579 & 0.634 & 0.445 \\
\hline No of Firms & 248 & 169 & 185 & 130 \\
\hline
\end{tabular}
and proportion of firms that reject the hypothesis that the parameters are equal to zero or constant.

${ }^{a}$ Proportion out of total number of firm $=569{ }^{b}$ Includes 34 companies for which there was no break at the country level ${ }^{c}$ Proportion out of number of firms rejecting no breaks beyond country level $=292$ 


\section{Table 5 Foreign Company Local Beta Estimates}

Local market beta $\left(\beta^{i \ell}\right)$ estimate means, standard error means, and cross-sectional standard deviations for various market portfolios in the two equation system regressions: (i) $r_{t}^{\ell}=\alpha^{\ell}+\beta^{\ell} r_{t}^{u}+u_{t}^{\ell}$; and (ii) $r_{t}^{i \ell}=\alpha^{i \ell}+\beta^{i \ell} r_{t}^{\ell}+\beta^{i u} r_{t}^{u}+e_{t}^{i \ell}$ where $r_{t}^{\ell}, r_{t}^{u}$, and $r_{t}^{i \ell}$ are the excess returns of the local market, US market, and firm $i$ from country $\ell$, respectively, and where $\left\{\alpha^{\ell}, \beta^{\ell}, \alpha^{i \ell}, \beta^{i \ell}, \beta^{i u}\right\}$ are parameters for country $\ell$ and firm $i$.

\begin{tabular}{|c|c|c|c|c|c|}
\hline Portfolio & Estimate & $\begin{array}{c}{\text { Period } \mathbf{1}^{a}}^{(\tau=1)} \\
\end{array}$ & $\begin{array}{c}\text { Period 2 } \\
(\tau=2)\end{array}$ & $\begin{array}{c}\text { Period } 3 \\
(\tau=3)\end{array}$ & $\begin{array}{c}\text { Period } 4 \\
(\tau=4)\end{array}$ \\
\hline \multicolumn{6}{|c|}{ Panel A: All Countries Market Weighted Vs. Equally Weighted } \\
\hline \multirow{5}{*}{$\begin{array}{l}\text { Market } \\
\text { Weighted }\end{array}$} & $\beta^{i \ell}$ Mean & 0.659 & 0.754 & 0.879 & 0.922 \\
\hline & Std Err Mean & 0.079 & 0.094 & 0.095 & 0.082 \\
\hline & $\operatorname{Corr}\left(r^{\ell}, r^{u}\right)$ & 0.223 & 0.187 & 0.214 & 0.236 \\
\hline & $\beta^{i \ell} \mathrm{St}$ Dev & 0.523 & 0.646 & 0.592 & 0.472 \\
\hline & No. of Obs & 570 & 435 & 222 & 52 \\
\hline \multirow{5}{*}{$\begin{array}{l}\text { Equally } \\
\text { Weighted }\end{array}$} & $\beta^{i \ell}$ Mean & 0.698 & 0.717 & 0.821 & 0.800 \\
\hline & Std Err Mean & 0.125 & 0.132 & 0.116 & 0.097 \\
\hline & $\operatorname{Corr}\left(r^{\ell}, r^{u}\right)$ & 0.223 & 0.187 & 0.214 & 0.236 \\
\hline & $\beta^{i \ell} \mathrm{St}$ Dev & 0.523 & 0.646 & 0.592 & 0.472 \\
\hline & No. of Obs & 570 & 435 & 222 & 52 \\
\hline \multicolumn{6}{|c|}{ Panel B: Market Weighted Developed Vs. Emerging } \\
\hline \multirow{5}{*}{$\begin{array}{l}\text { Market } \\
\text { Weighted }\end{array}$} & $\beta^{i \ell}$ Mean & 0.697 & 0.781 & 0.892 & 0.934 \\
\hline & Std Err Mean & 0.123 & 0.143 & 0.095 & 0.082 \\
\hline & $\operatorname{Corr}\left(r^{\ell}, r^{u}\right)$ & 0.236 & 0.191 & 0.214 & 0.238 \\
\hline & $\beta^{i \ell} \mathrm{St}$ Dev & 0.515 & 0.637 & 0.612 & 0.491 \\
\hline & No. of Obs & 386 & 303 & 165 & 37 \\
\hline \multirow{5}{*}{$\begin{array}{l}\text { Equally } \\
\text { Weighted }\end{array}$} & $\beta^{i \ell}$ Mean & 0.334 & 0.471 & 0.648 & 0.554 \\
\hline & Std Err Mean & 0.079 & 0.091 & 0.087 & 0.076 \\
\hline & $\operatorname{Corr}\left(r^{\ell}, r^{u}\right)$ & 0.110 & 0.134 & 0.195 & 0.174 \\
\hline & $\beta^{i \ell} \mathrm{St}$ Dev & 0.533 & 0.677 & 0.534 & 0.389 \\
\hline & No. of Obs & 166 & 119 & 53 & 15 \\
\hline
\end{tabular}


Table 5 Foreign Company Local Beta Estimates (cont.)

\begin{tabular}{|c|c|c|c|c|c|}
\hline Portfolio & Estimate & $\begin{array}{c}\text { Period } 1 \\
(\tau=1)\end{array}$ & $\begin{array}{c}\text { Period 2 } \\
(\tau=2)\end{array}$ & $\begin{array}{c}\text { Period } 3 \\
\quad(\tau=3)\end{array}$ & $\begin{array}{c}\text { Period } 4 \\
\quad(\tau=4)\end{array}$ \\
\hline \multicolumn{6}{|c|}{ Panel C: Market Weighted by Region } \\
\hline \multirow{5}{*}{ Asia } & $\beta^{i \ell}$ Mean & 0.260 & 0.315 & 0.366 & 0.843 \\
\hline & Std Err Mean & 0.076 & 0.081 & 0.074 & 0.054 \\
\hline & $\operatorname{Corr}\left(r^{\ell}, r^{u}\right)$ & 0.072 & 0.076 & 0.117 & 0.313 \\
\hline & $\beta^{i \ell} \mathrm{St}$ Dev & 0.544 & 0.774 & 0.586 & 0.534 \\
\hline & No. of Obs & 94 & 63 & 30 & 8 \\
\hline \multirow{5}{*}{ Europe } & $\beta^{\ell}$ Mean & 0.734 & 0.850 & 0.948 & 0.966 \\
\hline & Std Err Mean & 0.134 & 0.160 & 0.098 & 0.085 \\
\hline & $\operatorname{Corr}\left(r^{\ell}, r^{u}\right)$ & 0.261 & 0.209 & 0.218 & 0.233 \\
\hline & $\beta^{i \ell} \mathrm{St}$ Dev & 0.518 & 0.643 & 0.624 & 0.559 \\
\hline & No. of Obs & 217 & 173 & 92 & 23 \\
\hline \multirow{5}{*}{$\begin{array}{l}\text { Middle } \\
\text { East \& } \\
\text { Africa }\end{array}$} & $\beta^{i \ell}$ Mean & 0.316 & 0.214 & 0.052 & $\mathrm{n} / \mathrm{a}$ \\
\hline & Std Err Mean & 0.084 & 0.077 & 0.096 & $\mathrm{n} / \mathrm{a}$ \\
\hline & $\operatorname{Corr}\left(r^{\ell}, r^{u}\right)$ & 0.094 & 0.097 & 0.012 & $\mathrm{n} / \mathrm{a}$ \\
\hline & $\beta^{i \ell} \mathrm{St}$ Dev & 0.499 & 0.599 & 0.435 & $\mathrm{n} / \mathrm{a}$ \\
\hline & No. of Obs & 19 & 14 & 5 & $\mathrm{n} / \mathrm{a}$ \\
\hline \multirow{5}{*}{$\begin{array}{l}\text { North } \\
\text { America }\end{array}$} & $\beta^{i \ell}$ Mean & 0.813 & 0.689 & 1.164 & 0.607 \\
\hline & Std Err Mean & 0.142 & 0.146 & 0.128 & 0.110 \\
\hline & $\operatorname{Corr}\left(r^{\ell}, r^{u}\right)$ & 0.165 & 0.112 & 0.233 & 0.135 \\
\hline & $\beta^{i \ell} \mathrm{St}$ Dev & 0.529 & 0.670 & 0.705 & 0.434 \\
\hline & No. of Obs & 145 & 107 & 50 & 9 \\
\hline \multirow{5}{*}{ Oceania } & $\beta^{i \ell}$ Mean & 0.939 & 0.912 & 0.813 & 0.941 \\
\hline & Std Err Mean & 0.059 & 0.067 & 0.060 & 0.057 \\
\hline & $\operatorname{Corr}\left(r^{\ell}, r^{u}\right)$ & 0.347 & 0.287 & 0.306 & 0.260 \\
\hline & $\beta^{i \ell} \mathrm{St} \mathrm{Dev}$ & 0.333 & 0.503 & 0.270 & 0.066 \\
\hline & No. of Obs & 21 & 17 & 12 & 2 \\
\hline \multirow{5}{*}{$\begin{array}{l}\text { South } \\
\text { America }\end{array}$} & $\beta^{i \ell}$ Mean & 0.970 & 0.937 & 1.062 & 0.788 \\
\hline & Std Err Mean & 0.070 & 0.075 & 0.078 & 0.086 \\
\hline & $\operatorname{Corr}\left(r^{\ell}, r^{u}\right)$ & 0.375 & 0.309 & 0.329 & 0.232 \\
\hline & $\beta^{i \ell} \mathrm{St}$ Dev & 0.412 & 0.406 & 0.290 & 0.262 \\
\hline & No. of Obs & 68 & 57 & 33 & 10 \\
\hline
\end{tabular}

$a$ "Periods" are defined as intervals over which the company-specific parameter vector is stable. Thus, they do not correspond to the same time periods for all companies. 


\section{Table 6 Foreign Company US Beta Estimates}

US market beta $\left(\beta^{i u}\right)$ estimate means, standard error means, and cross-sectional standard deviations for various market portfolios in the two equation system regressions: (i) $r_{t}^{\ell}=\alpha^{\ell}+\beta^{\ell} r_{t}^{u}+u_{t}^{\ell}$; and (ii) $r_{t}^{i \ell}=\alpha^{i \ell}+\beta^{i \ell} r_{t}^{\ell}+\beta^{i u} r_{t}^{u}+e_{t}^{i \ell}$ where $r_{t}^{\ell}, r_{t}^{u}$, and $r_{t}^{i \ell}$ are the excess returns of the local market, US market, and firm $i$ from country $\ell$, respectively, and where $\left\{\alpha^{\ell}, \beta^{\ell}, \alpha^{i \ell}, \beta^{i \ell}, \beta^{i u}\right\}$ are parameters for country $\ell$ and firm $i$.

\begin{tabular}{|c|c|c|c|c|c|}
\hline Portfolio & Estimate & $\begin{array}{c}\text { Period 1 } \\
(\tau=1)\end{array}$ & $\begin{array}{c}\text { Period 2 } \\
(\tau=2)\end{array}$ & $\begin{array}{c}\text { Period 3 } \\
(\tau=3)\end{array}$ & $\begin{array}{c}\text { Period 4 } \\
(\tau=4)\end{array}$ \\
\hline
\end{tabular}

Panel A: All Countries Market Weighted Vs. Equally Weighted

\begin{tabular}{|l|c|c|c|c|c|}
\hline \multirow{3}{*}{ Market } & $\beta^{\text {iu }}$ Mean & 0.455 & 0.792 & 0.858 & 0.995 \\
& Std Err Mean & 0.127 & 0.128 & 0.077 & 0.065 \\
& Corr $\left(r^{i}, r^{u}\right)$ & 0.156 & 0.224 & 0.257 & 0.315 \\
& $\beta^{\text {iu }}$ St Dev & 0.555 & 0.678 & 0.554 & 0.552 \\
& No. of Obs & 570 & 435 & 222 & 52 \\
\hline \multirow{4}{*}{ Equally } & $\beta^{\text {iu } \text { Mean }}$ & 0.624 & 0.858 & 0.862 & 0.882 \\
Weighted & Std Err Mean & 0.131 & 0.121 & 0.106 & 0.086 \\
& Corr $\left(r^{i}, r^{u}\right)$ & 0.156 & 0.224 & 0.257 & 0.315 \\
& $\beta^{\text {iu }}$ St Dev & 0.555 & 0.678 & 0.554 & 0.552 \\
& No. of Obs & 570 & 435 & 222 & 52 \\
\hline
\end{tabular}

\section{Panel B: Market Weighted Developed Vs. Emerging}

\begin{tabular}{|l|c|c|c|c|c|}
\hline \multirow{3}{*}{ Market } & $\beta^{\text {iu }}$ Mean & 0.432 & 0.776 & 0.842 & 1.003 \\
& Std Err Mean & 0.125 & 0.128 & 0.075 & 0.064 \\
& Corr $\left(r^{i}, r^{u}\right)$ & 0.152 & 0.222 & 0.257 & 0.319 \\
& $\beta^{\text {iu }}$ St Dev & 0.527 & 0.645 & 0.541 & 0.551 \\
& No. of Obs & 386 & 303 & 165 & 37 \\
\hline \multirow{3}{*}{ Equally } & $\beta^{\text {iu }}$ Mean & 0.624 & 0.979 & 1.133 & 0.752 \\
Weighted & Std Err Mean & 0.148 & 0.125 & 0.115 & 0.093 \\
& Corr $\left(r^{i}, r^{u}\right)$ & 0.181 & 0.250 & 0.274 & 0.199 \\
& $\beta^{\text {iu }}$ St Dev & 0.589 & 0.770 & 0.565 & 0.554 \\
& No. of Obs & 166 & 119 & 53 & 15 \\
\hline
\end{tabular}


Table 6 Foreign Company US Beta Estimates (cont.)

\begin{tabular}{|c|c|c|c|c|c|}
\hline Portfolio & Estimate & $\begin{array}{c}\text { Period } 1 \\
(\tau=1)\end{array}$ & $\begin{array}{c}\text { Period 2 } \\
(\tau=2)\end{array}$ & $\begin{array}{c}\text { Period } 3 \\
(\tau=3)\end{array}$ & $\begin{array}{c}\text { Period } 4 \\
(\tau=4)\end{array}$ \\
\hline \multicolumn{6}{|c|}{ Panel C: Market Weighted by Region } \\
\hline \multirow{5}{*}{ Asia } & $\beta^{i u}$ Mean & 0.355 & 0.608 & 0.646 & 0.579 \\
\hline & Std Err Mean & 0.105 & 0.098 & 0.084 & 0.059 \\
\hline & $\operatorname{Corr}\left(r^{i}, r^{u}\right)$ & 0.131 & 0.169 & 0.176 & 0.192 \\
\hline & $\beta^{i u} \mathrm{St}$ Dev & 0.577 & 0.498 & 0.574 & 0.411 \\
\hline & No. of Obs & 94 & 63 & 30 & 8 \\
\hline \multirow{5}{*}{ Europe } & $\beta^{i u}$ Mean & 0.445 & 0.827 & 0.870 & 1.035 \\
\hline & Std Err Mean & 0.137 & 0.141 & 0.074 & 0.063 \\
\hline & $\operatorname{Corr}\left(r^{i}, r^{u}\right)$ & 0.163 & 0.242 & 0.270 & 0.343 \\
\hline & $\beta^{i u} \mathrm{St}$ Dev & 0.539 & 0.601 & 0.573 & 0.587 \\
\hline & No. of Obs & 217 & 173 & 92 & 23 \\
\hline \multirow{5}{*}{$\begin{array}{l}\text { Middle } \\
\text { East \& } \\
\text { Africa }\end{array}$} & $\beta^{\text {iu }}$ Mean & 0.732 & 0.452 & 0.866 & $\mathrm{n} / \mathrm{a}$ \\
\hline & Std Err Mean & 0.182 & 0.118 & 0.131 & $\mathrm{n} / \mathrm{a}$ \\
\hline & $\operatorname{Corr}\left(r^{i}, r^{u}\right)$ & 0.141 & 0.143 & 0.182 & $\mathrm{n} / \mathrm{a}$ \\
\hline & $\beta^{i u} \mathrm{St}$ Dev & 0.653 & 0.716 & 0.293 & $\mathrm{n} / \mathrm{a}$ \\
\hline & No. of Obs & 19 & 14 & 5 & $\mathrm{n} / \mathrm{a}$ \\
\hline \multirow{5}{*}{$\begin{array}{l}\text { North } \\
\text { America }\end{array}$} & $\beta^{i u}$ Mean & 0.717 & 0.898 & 0.986 & 1.157 \\
\hline & Std Err Mean & 0.120 & 0.109 & 0.099 & 0.088 \\
\hline & $\operatorname{Corr}\left(r^{i}, r^{u}\right)$ & 0.190 & 0.207 & 0.269 & 0.258 \\
\hline & $\beta^{i u} \mathrm{St}$ Dev & 0.536 & 0.810 & 0.555 & 0.580 \\
\hline & No. of Obs & 145 & 107 & 50 & 9 \\
\hline \multirow{5}{*}{ Oceania } & $\beta^{i u}$ Mean & 0.316 & 0.682 & 0.793 & 1.048 \\
\hline & Std Err Mean & 0.065 & 0.070 & 0.061 & 0.057 \\
\hline & $\operatorname{Corr}\left(r^{i}, r^{u}\right)$ & 0.094 & 0.192 & 0.252 & 0.288 \\
\hline & $\beta^{i u}$ St Dev & 0.257 & 0.721 & 0.361 & 0.086 \\
\hline & No. of Obs & 21 & 17 & 12 & 2 \\
\hline \multirow{5}{*}{$\begin{array}{l}\text { South } \\
\text { America }\end{array}$} & $\beta^{i u}$ Mean & 0.779 & 0.992 & 1.192 & 0.920 \\
\hline & Std Err Mean & 0.132 & 0.112 & 0.090 & 0.093 \\
\hline & $\operatorname{Corr}\left(r^{i}, r^{u}\right)$ & 0.164 & 0.221 & 0.315 & 0.248 \\
\hline & $\beta^{i u}$ St Dev & 0.512 & 0.688 & 0.538 & 0.563 \\
\hline & No. of Obs & 68 & 57 & 33 & 10 \\
\hline
\end{tabular}

$a$ "Periods" are defined as intervals over which the company-specific parameter vector is stable. Thus, they do not correspond to the same time periods for all companies. 


\section{Table 7 Foreign Company and Market Return Estimates Before and After Cross-Listing}

Parameter estimate means, standard error means, and cross-sectional standard deviations before and after cross-listing. Panel A gives results for the market return regressions reported in Table 3 and Figure 1: $r_{t}^{\ell}=\alpha^{\ell}+\beta^{\ell} r_{t}^{u}+u_{t}^{\ell}$; Panel B gives results for the company return regressions reported in Tables 5 and 6 and Figure 2: $r_{t}^{i \ell}=\alpha^{i \ell}+\beta^{i \ell} r_{t}^{\ell}+\beta^{i u} r_{t}^{u}+e_{t}^{i \ell}$.The columns headed "Before Listing,"

"Only After Listing," and "After and During Listing" give, respectively, statistics performed on parameter averages across subperiods before cross-listing, across subperiods that break after cross-listing, and across the subperiod during cross-listing and the subperiods after cross-listing.

\begin{tabular}{|l|c|c|c|c|}
\hline Portfolio & Estimate & Before Listing & $\begin{array}{c}\text { Only After } \\
\text { Listing }\end{array}$ & $\begin{array}{c}\text { After and } \\
\text { During Listing }\end{array}$ \\
\hline \multicolumn{5}{|c|}{ Panel A: Market Return Regressions } \\
\hline \multirow{3}{*}{ Warket } & $\beta^{\ell}$ Mean & 0.348 & 0.830 & 0.594 \\
& Std Err Mean & 0.047 & 0.047 & 0.047 \\
& Corr $\left(r^{\ell}, r^{u}\right)$ & 0.198 & 0.375 & 0.289 \\
& $\beta^{\ell}$ St Dev & 0.248 & 0.260 & 0.199 \\
& No. of Obs & 42 & 35 & 35 \\
\hline \multirow{4}{*}{ Wqually } & $\beta^{\ell}$ Mean & 0.378 & 0.882 & 0.634 \\
& Std Err Mean & 0.063 & 0.063 & 0.062 \\
& Corr $\left(r^{\ell}, r^{u}\right)$ & 0.198 & 0.375 & 0.289 \\
& $\beta^{\ell}$ St Dev & 0.248 & 0.260 & 0.199 \\
& No. of Obs & 42 & 35 & 35 \\
\hline
\end{tabular}


Table 7 Foreign Company and Market Return Estimates Before and After Cross-Listing (cont.)

\begin{tabular}{|l|c|c|c|c|}
\hline Portfolio & Estimate & Before Listing & $\begin{array}{c}\text { Only After } \\
\text { Listing }\end{array}$ & $\begin{array}{c}\text { After and } \\
\text { During Listing }\end{array}$ \\
\hline \multicolumn{5}{|c|}{ Panel B: Foreign Company Return Regressions } \\
\hline \multirow{5}{*}{ Market } & $\beta^{i \ell}$ Mean & 0.647 & 0.758 & 0.766 \\
& Std Err Mean & 0.079 & 0.095 & 0.088 \\
& Corr $\left(r^{i}, r^{\ell}\right)$ & 0.220 & 0.179 & 0.220 \\
& $\beta^{i \ell}$ St Dev & 0.527 & 0.563 & 0.492 \\
& No. of Obs & 570 & 368 & 390 \\
\cline { 2 - 5 } & $\beta^{\text {iu } \text { Mean }}$ & 0.486 & 0.970 & 0.740 \\
& Std Err Mean & 0.085 & 0.078 & 0.080 \\
& Corr $\left(r^{i}, r^{u}\right)$ & 0.168 & 0.288 & 0.227 \\
& $\beta^{i u}$ St Dev & 0.514 & 0.544 & 0.388 \\
& No. of Obs & 570 & 368 & 390 \\
\hline \multirow{5}{*}{ Equally } & $\beta^{i \ell}$ Mean & 0.696 & 0.691 & 0.723 \\
& Std Err Mean & 0.125 & 0.124 & 0.124 \\
& Corr $\left(r^{i}, r^{\ell}\right)$ & 0.220 & 0.179 & 0.220 \\
& $\beta^{i \ell}$ St Dev & 0.527 & 0.563 & 0.492 \\
& No. of Obs & 570 & 368 & 390 \\
\cline { 2 - 5 } & $\beta^{\text {iu } \text { Mean }}$ & 0.639 & 0.967 & 0.800 \\
& Std Err Mean & 0.128 & 0.110 & 0.117 \\
& Corr $\left(r^{i}, r^{u}\right)$ & 0.168 & 0.288 & 0.227 \\
& $\beta^{i u}$ St Dev & 0.514 & 0.544 & 0.388 \\
& No. of Obs & 570 & 368 & 390 \\
\hline
\end{tabular}




\section{Table A: Comparison of Emerging Market Break Points}

Table compares the results from the text with those of Bekaert, Harvey, and Lumsdaine (2002) for the countries in common. The reported Bekaert, Harvey, and Lumsdaine (2002) results are from their Table 2 for A. Mean break and B. All parameter break. The sample period for BHL differs by country, but they report the maximum sample period in Bekaert and Harvey (2000), Table II. *,**,*** indicate significance levels of $10 \%, 5 \%$, and $1 \%$, respectively. \# note that the ending date for all countries is October 2009.

\begin{tabular}{|c|c|c|c|c|c|c|c|c|c|}
\hline \multirow[b]{3}{*}{ Country } & \multicolumn{2}{|c|}{$\begin{array}{l}\text { BHL Median Estimates : Max Sample Period } \\
\text { Jan-76 to Dec-95 }\end{array}$} & \multicolumn{7}{|c|}{ Sup(F) Break-Point Estimates: } \\
\hline & \multirow{2}{*}{$\begin{array}{c}\text { A. Mean break } \\
\text { Median }\end{array}$} & \multirow{2}{*}{$\begin{array}{c}\begin{array}{c}\text { B. All parameters } \\
\text { break }\end{array} \\
\text { Median }\end{array}$} & \multirow{2}{*}{$\begin{array}{c}\text { Sample Start Date }^{\#} \\
\text { Maximum Overlap } \\
\text { in Years }\end{array}$} & \multicolumn{3}{|c|}{ Min Subsample: $\varepsilon=15 \%$} & \multicolumn{3}{|c|}{ Min Subsample: $\varepsilon=5 \%$} \\
\hline & & & & Break 1 & Break 2 & $\begin{array}{c}\text { Break } \\
3\end{array}$ & Break 1 & Break 2 & Break 3 \\
\hline Argentina & Jun-85 & Jul-89 & $\begin{array}{l}\text { Aug-93 } \\
2.4\end{array}$ & Jan-99*** & & & Jan-99** & & \\
\hline Brazil & Sep-83 & Sep-83 & $\begin{array}{c}\text { Jul-94 } \\
1.5\end{array}$ & Oct $-02 * * *$ & & & Oct-02*** & Dec- $08 * *$ & \\
\hline Chile & Jul-80** & Nov-79*** & $\begin{array}{c}\text { Jul-89 } \\
6.4\end{array}$ & Jan-94*** & $\begin{array}{l}\text { Mar- } \\
03^{* * *}\end{array}$ & $\begin{array}{l}\text { Jan- } \\
99 *\end{array}$ & Jan-91*** & $\begin{array}{l}\text { Mar- } \\
03^{* * *}\end{array}$ & \\
\hline Colombia & Apr-94 & Feb-92** & $\begin{array}{c}\text { Mar-92 } \\
3.8\end{array}$ & Oct- $03 * * *$ & & & Oct-03*** & & \\
\hline Greece & Nov-85* & Aug-90* & $\begin{array}{c}\text { Jan-90 } \\
6.0\end{array}$ & Feb-06*** & & & Feb-06*** & & \\
\hline India & Apr-92 & Jun-90 & $\begin{array}{c}\text { Jan-90 } \\
6.0\end{array}$ & Apr-00*** & & & Apr-00*** & & \\
\hline Indonesia & Nov-91** & Nov-91** & $\begin{array}{c}\text { Jan-90 } \\
6.0\end{array}$ & & & & & & \\
\hline Korea & Apr-89 & Apr-89 & $\begin{array}{l}\text { Sep-87 } \\
8.3\end{array}$ & Sep-97*** & & & Sep-97*** & & \\
\hline Mexico & Jan-83 & Oct-87*** & $\begin{array}{c}\text { Jan-73 } \\
23.0\end{array}$ & $\begin{array}{l}\text { Nov- } \\
04 * * *\end{array}$ & & & Nov- $04 * * *$ & & \\
\hline Philippines & Aug-87*** & Aug-87*** & $\begin{array}{c}\text { Jan-90 } \\
6.0\end{array}$ & & & & & & \\
\hline Portugal & Feb-88*** & Jan-88*** & $\begin{array}{c}\text { Jun-94 } \\
1.6\end{array}$ & $\begin{array}{l}\text { Nov- } \\
05^{* * *}\end{array}$ & & & Nov- $05^{* * *}$ & & \\
\hline Taiwan & Jun-89 & Jun-89 & $\begin{array}{c}\text { Jan-90 } \\
6.0\end{array}$ & Sep- $01^{* * *}$ & & & $\begin{array}{l}\text { May- } \\
90 * * *\end{array}$ & Jun-91*** & Sep- $01 * *$ \\
\hline Turkey & Aug-90 & Aug-90 & $\begin{array}{c}\text { Aug-93 } \\
2.4\end{array}$ & Oct- $00 * * *$ & & & Oct $-00 * * *$ & Feb- $02 * *$ & $\begin{array}{l}\text { Mar- } \\
03^{* *}\end{array}$ \\
\hline Venezuela & Feb-92 & Feb-92** & $\begin{array}{c}\text { Jan-73 } \\
23\end{array}$ & Feb-94* & Sep-98* & & Dec-90*** & & \\
\hline
\end{tabular}




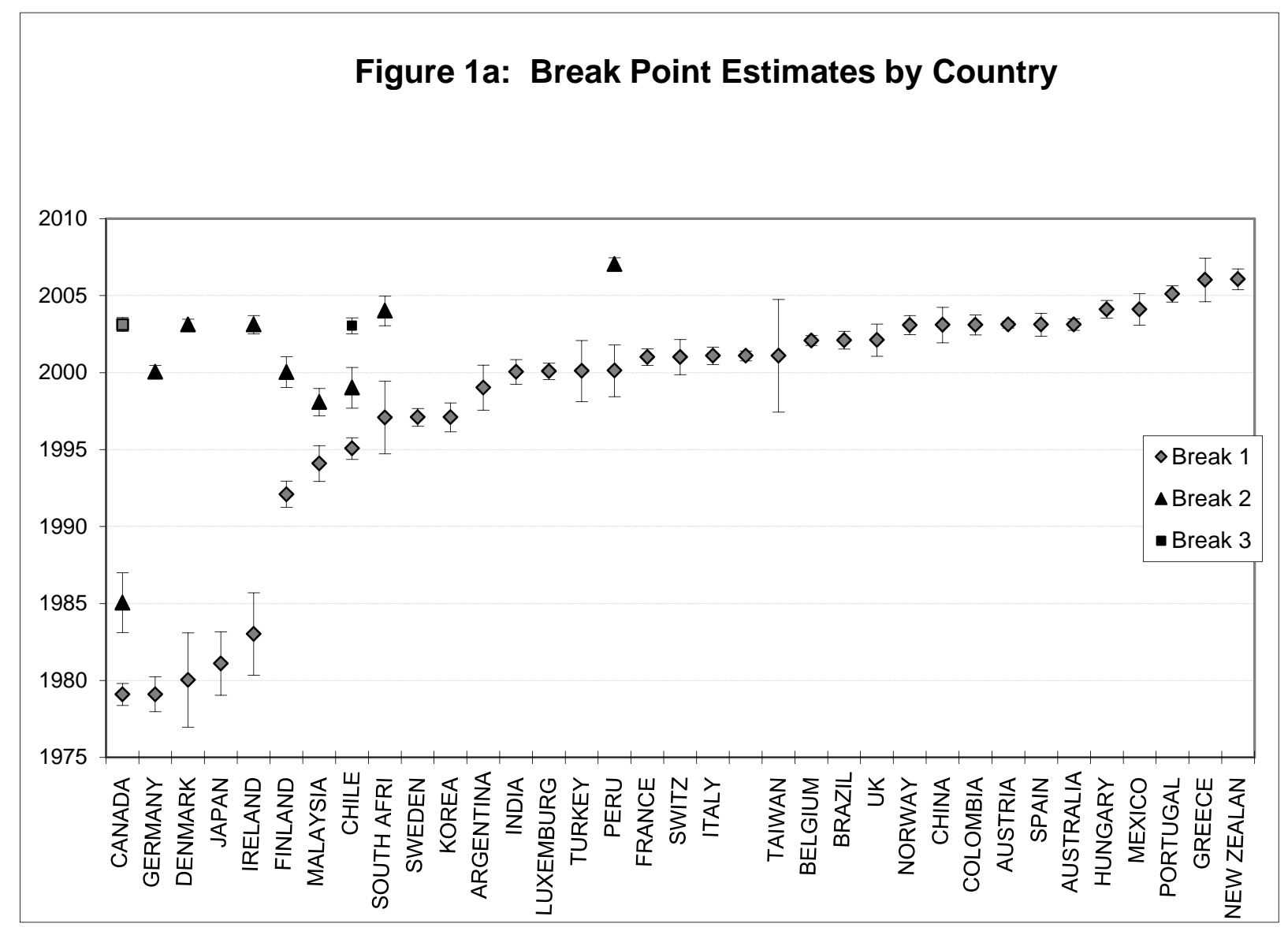


Figure $1 \mathrm{~b}$ : Distribution of Country Breaks

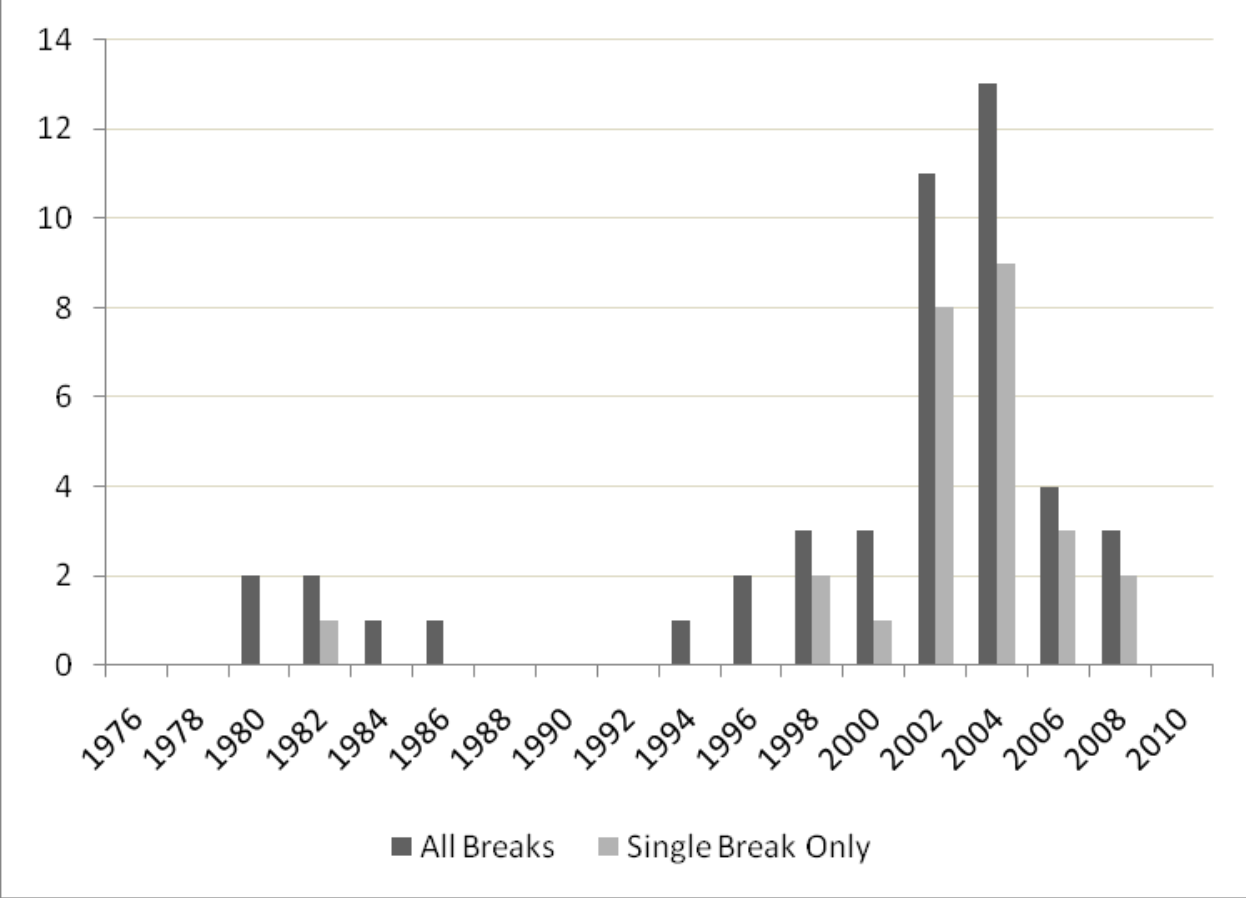


Figure 2: Break Point Estimates by Firm

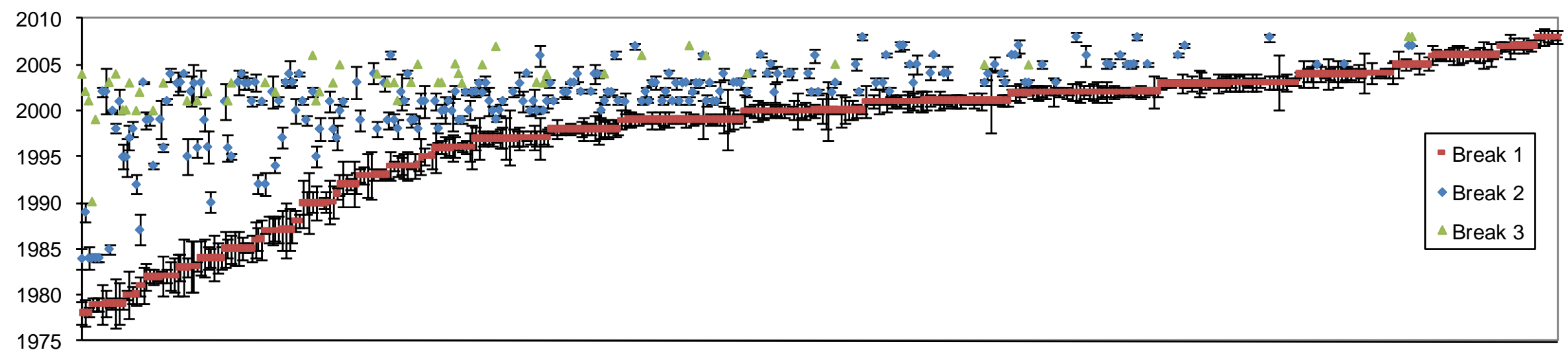

Firms Sorted by Initial Break Date 

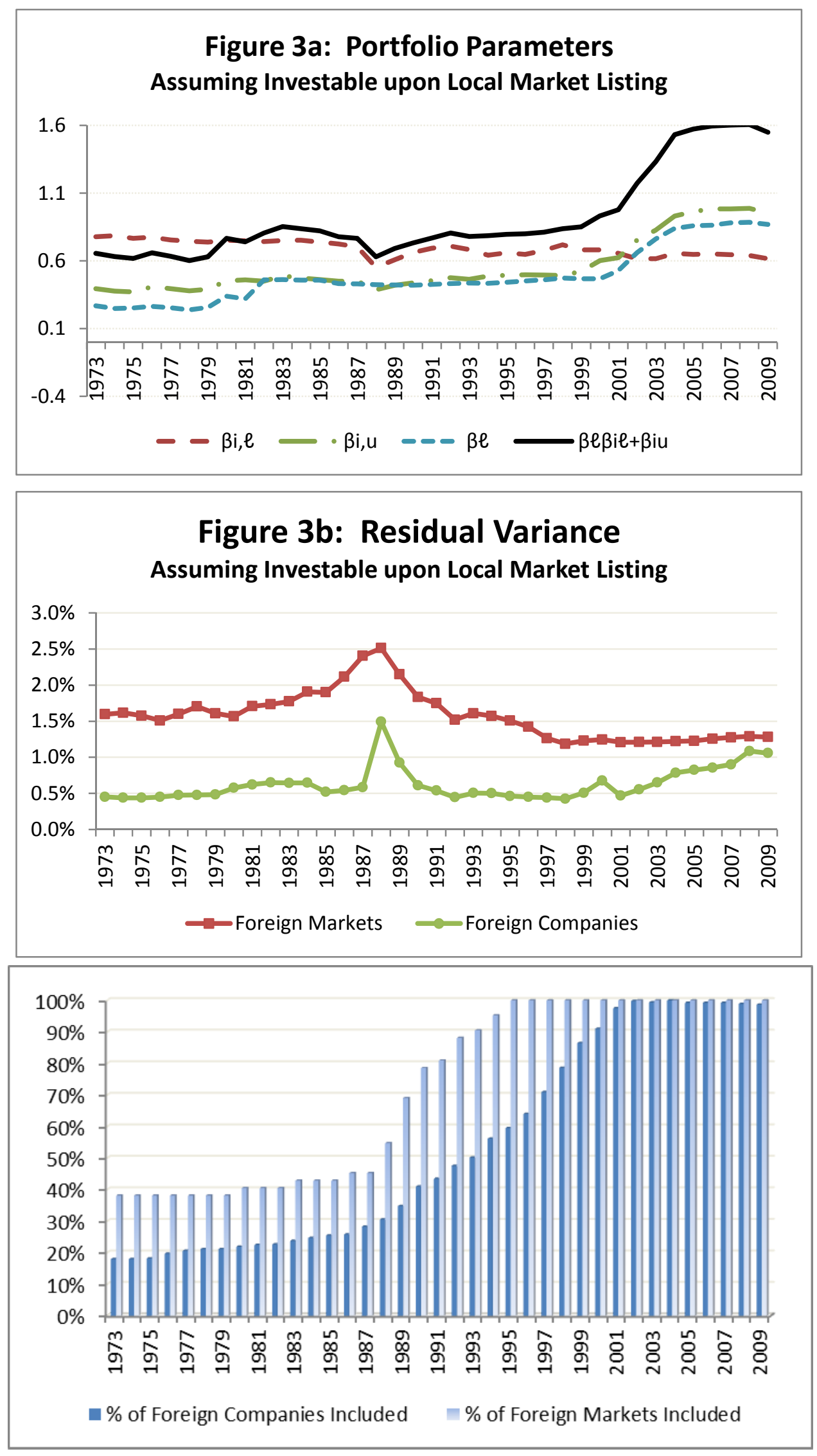


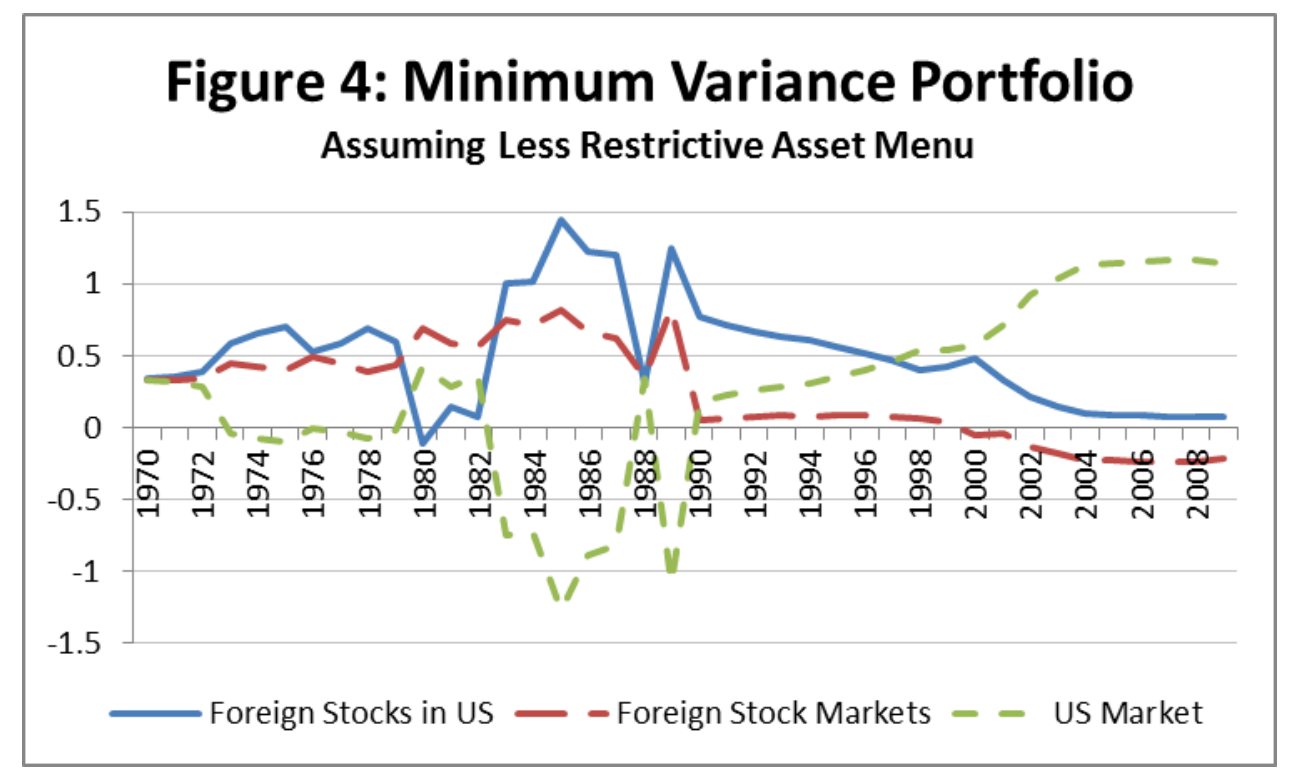




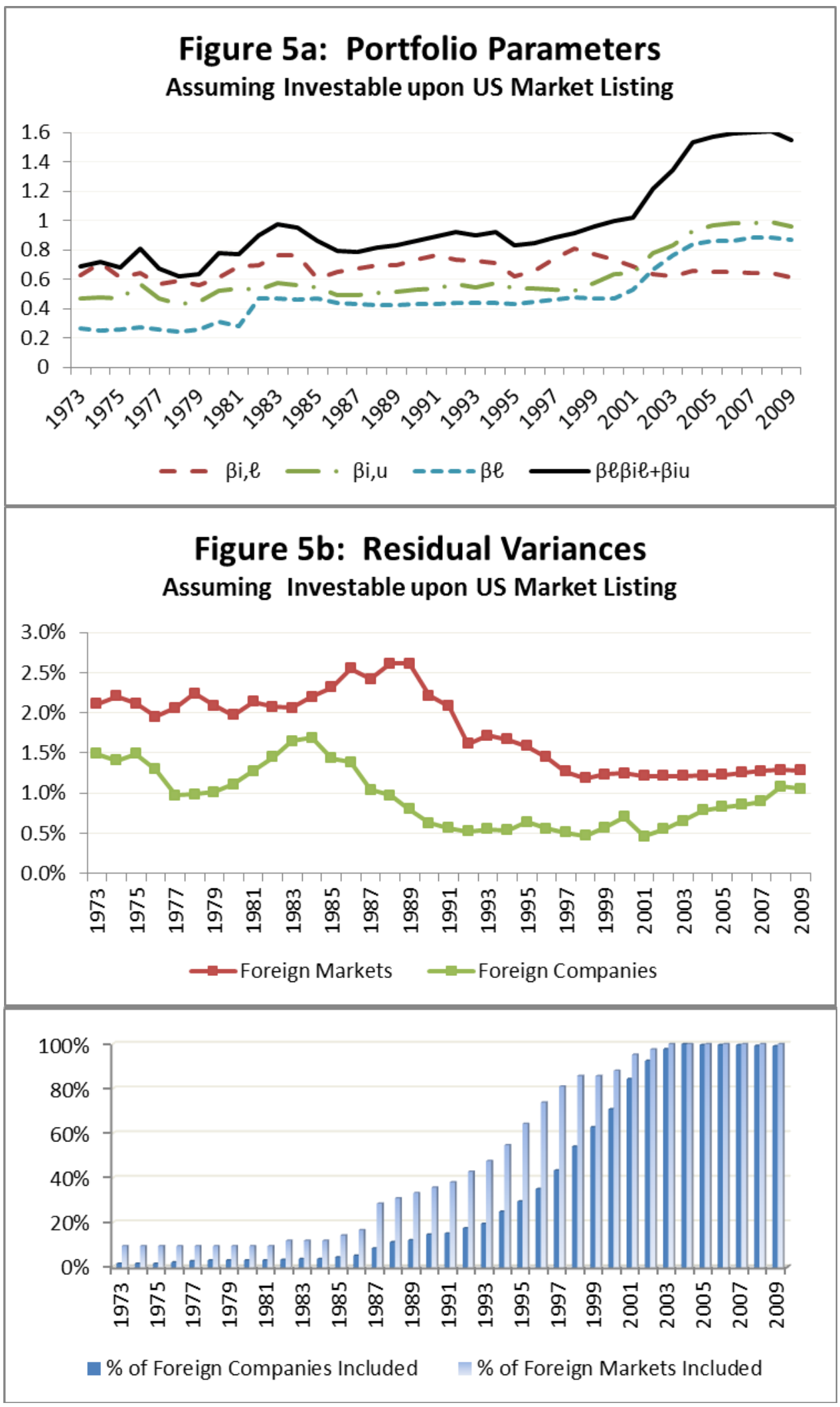




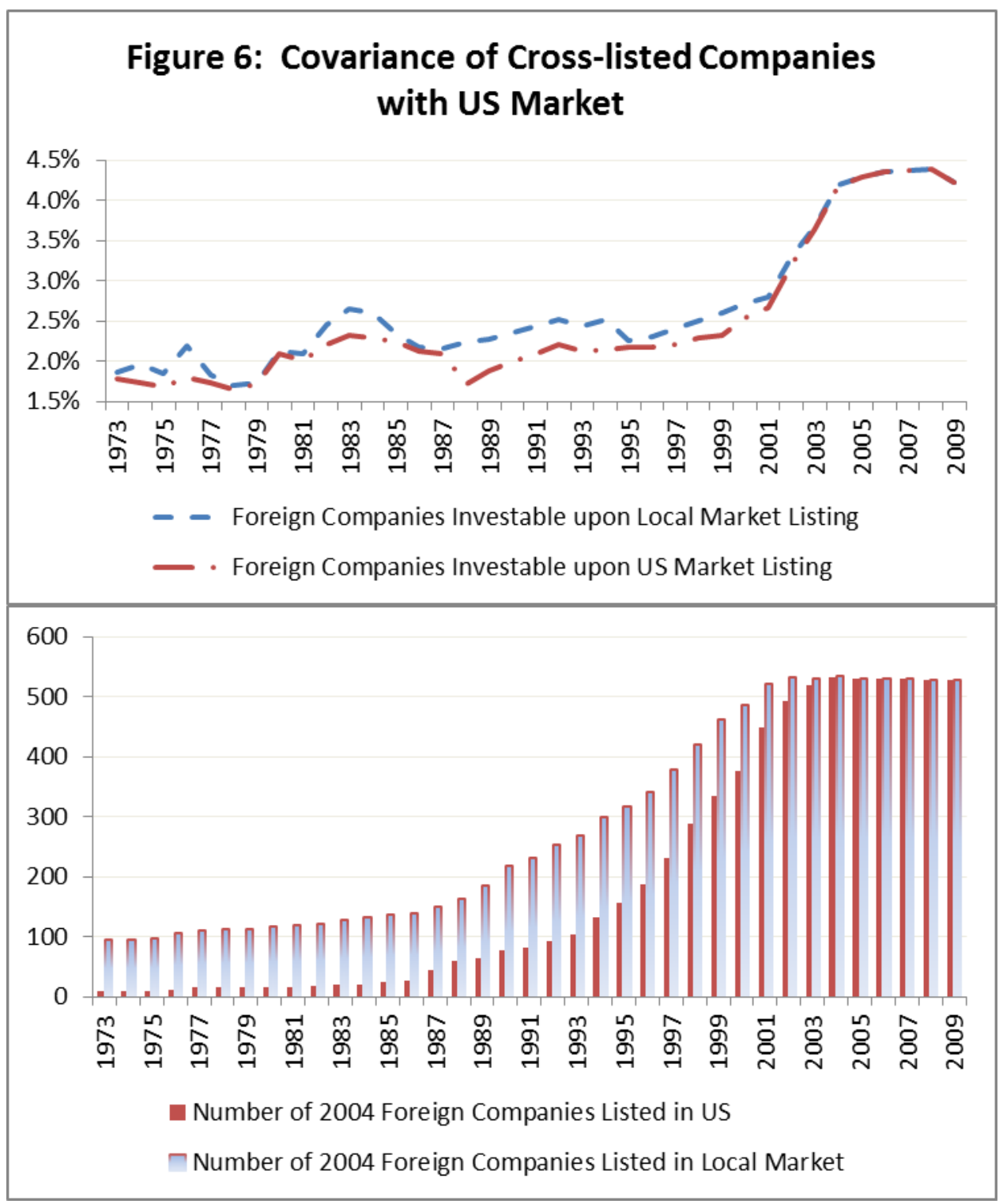




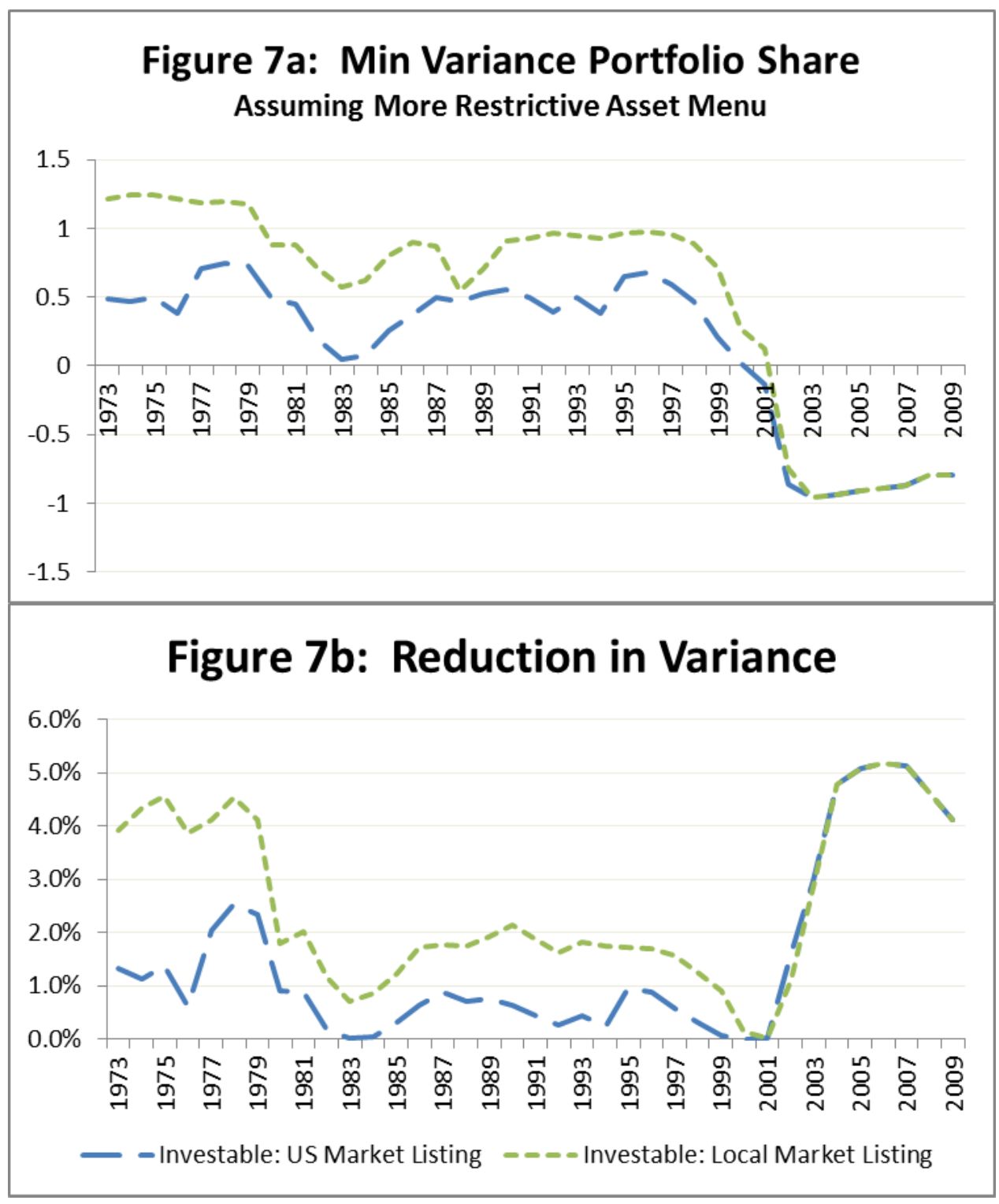




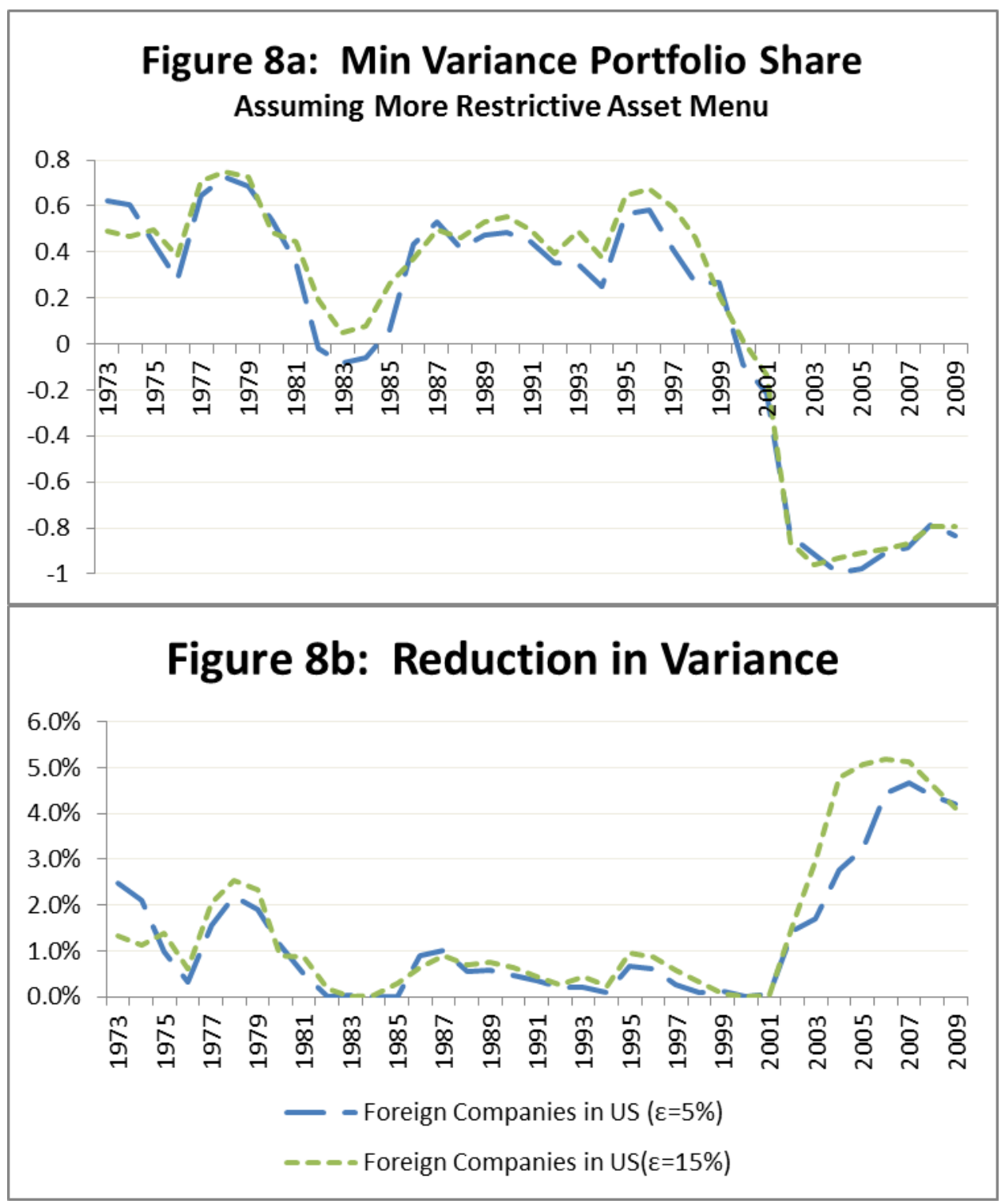

